\title{
Multitemporal Landslide Inventory and Activity Analysis by Means of Aerial Photogrammetry and LiDAR Techniques in an Area of Southern Spain
}

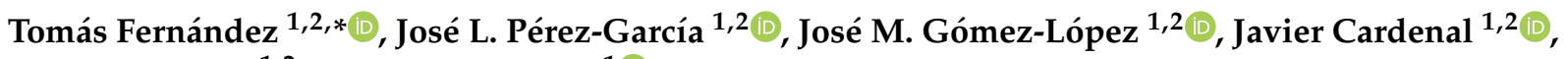 \\ Francisco Moya ${ }^{1,2}$ and Jorge Delgado ${ }^{1}$ D \\ 1 Department of Cartographic, Geodetic and Photogrammetric Engineering, Campus de las Lagunillas s/n, \\ University of Jaén, 23071 Jaén, Spain; jlperez@ujaen.es (J.L.P.-G.); jglopez@ujaen.es (J.M.G.-L.); \\ jcardena@ujaen.es (J.C.); fmoya@ujaen.es (F.M.); jdelgado@ujaen.es (J.D.) \\ 2 Centre for Advanced Studies in Earth Sciences, Energy and Environment (CEACTEMA), \\ Campus de las Lagunillas s/n, University of Jaén, 23071 Jaén, Spain \\ * Correspondence: tfernan@ujaen.es; Tel.: +34-53-212843
}

check for updates

Citation: Fernández, T.;

Pérez-García, J.L.; Gómez-López, J.M.; Cardenal, J.; Moya, F.; Delgado, J. Multitemporal Landslide Inventory and Activity Analysis by Means of Aerial Photogrammetry and LiDAR Techniques in an Area of Southern Spain. Remote Sens. 2021, 13, 2110. https://doi.org/10.3390/rs13112110

Academic Editors: Federica Bardi, Giulia Dotta, Diego Di Martire, Qingkai Meng and Pierluigi Confuorto

Received: 31 March 2021

Accepted: 25 May 2021

Published: 27 May 2021

Publisher's Note: MDPI stays neutral with regard to jurisdictional claims in published maps and institutional affiliations.

Copyright: (c) 2021 by the authors. Licensee MDPI, Basel, Switzerland. This article is an open access article distributed under the terms and conditions of the Creative Commons Attribution (CC BY) license (https:// creativecommons.org/licenses/by/ $4.0 /)$.

\begin{abstract}
This paper deals with the use of aerial photogrammetry and LiDAR techniques to analyze landslide activity over a long time span-just over 32 years. The data correspond to several aerial surveys (1984, 1996, 2001, 2005, 2009, 2010, 2011, 2013 and 2016) covering an area of about $50 \mathrm{~km}^{2}$ along highway A-44, near Jaén (Southern Spain). An ad hoc combined photogrammetric and LiDAR aerial survey of 2010 was established as the reference flight. This flight was processed by means of direct orientation methods and iterative adjustments between both data sets. Meanwhile, historical flights available in public geographical data servers were oriented by transferring ground control points from the reference flight. Then, digital surface models (DSMs) and orthophotographs were generated, as well as the corresponding differential models (DoDs), which, after the application of filters and taking into account the estimated uncertainty of $\pm 1 \mathrm{~m}$, allowed us to identify true changes on the ground surface. This analysis, complemented by photointerpretation, led us to obtain a landslide multitemporal inventory in the study area that was analyzed in order to characterize the landslide type, morphology and activity. Three basic typologies were identified: rock falls-collapses, slides and flows. These types present different morphometric properties (area, perimeter and height interval) and are associated with different conditions (height, slope, orientation and lithology). Moreover, a set of monitoring areas, common for the different flights, was also used to analyze the activity throughout the study period. Thus, some more active periods were identified (2009-2010, 2010-2011, 2011-2013 and 1996-2001) among other less active ones (1984-1996, 2001-2005, 2005-2009 and 2013-2016), which are related to rainy events and dry years, respectively.
\end{abstract}

Keywords: multitemporal; landslide inventory; activity; photogrammetry; LiDAR; southern Spain

\section{Introduction}

The estimation of landslide activity and its dating is crucial in risk analyses, since it allows the determination of hazards in terms of spatiotemporal probability, one of the components of the risk equation [1]. Landslide dating is difficult in most cases, so it is usually reduced either to the direct dating of a reduced sample of individual landslides or to the dating of the triggering factors in order to determine the activity in an indirect manner. Direct dating is performed with complex and sometimes invasive techniques, which restricts its use generally to individual cases. For wider areas, geomorphological analysis is a primary tool for obtaining multitemporal inventories [2,3].

This geomorphological analysis is usually based on photointerpretation, which is a time-consuming technique and introduces a certain subjectivity into the analysis $[3,4]$. However, in recent years, geomatic techniques have opened up an interesting research line 
in landslide studies because collections of aerial photographs and satellite images have become available, with information on the ground surface from the past.

In this sense, remote sensing (RS) and geographical information system (GIS) techniques are basic tools for landslide analysis $[5,6]$, as they allow the study and mapping of areas of different extents with the required resolution and accuracy. These techniques can be based on passive, optical and thermal sensors, or active, LiDAR and synthetic aperture radar (SAR) instruments $[7,8]$. These systems, on board space and airborne platforms including unmanned aerial systems (UAS), allow the development of 3D and multitemporal approaches. Furthermore, RS techniques are also applied to landslide recognition and inventory, monitoring, analysis and prediction.

In high-resolution studies with landslides of a diachronic evolution in which processes of reactivation take place, aerial photogrammetry is suitable. Therefore, its use is increasingly widespread [9-14]. Photogrammetry is sometimes combined with other methods, such as LiDAR techniques [15-18], Global Navigation Satellite Systems (GNSS), [18] or the digitization of old maps [15]. In these studies, image block orientation is based on conventional techniques of aerotriangulation, using a reduced number of ground control points (GCPs) measured on the field by GNSS. Recently, the increasing use of unmanned or remotely piloted aerial systems (UAS or RPAS), combined with structure from motion (SfM) and multiple video stereo (MVS) approaches [19], have extended the application of photogrammetric techniques to very high-resolution [20-23] or even ultrahigh-resolution studies [24]. In some cases, experiments for direct orientation without the use of GCPs have also been undertaken [23].

Once the images have been oriented, photogrammetric products, such as digital surface models (DSMs), digital terrain models (DTMs) and orthophotographs, can be generated. From the DSMs/DTMs of successive epochs, quantitative approaches have been developed, such as the calculation of differential models (DoDs), topographic profiles and volumetric calculations [9-11,14-18,20-24]. In addition, in some cases, the 3D displacement vectors are calculated $[18,20-22,24]$, and observations are made for the qualitative characterization of movements through the interpretation of orthoimages $[9,11,14,16,17,21,24]$ and image analysis $[13,17]$.

Meanwhile, LiDAR techniques are currently being extensively used in landslide research. They allow the creation of DSMs and DTMs with high resolution and precision. These models are used to obtain DEM derivatives, such as slope and shaded or curvature models, from which landslides and relief features are extracted [25-27]; to apply object-based or machine learning techniques to detect landslides [28-30]; and to calculate DoDs between different dates [15-17,29,31-34].

Most of these studies, both photogrammetric and/or LiDAR approaches, are focused on single movements in unstable areas, although some of them are applied to detect landslides and elaborate inventories [13,26,28-31,33,34].

In this paper, aerial LiDAR and photogrammetry techniques were integrated in order to elaborate a multitemporal landslide inventory and monitor the landslide activity in a relative wide area of about $50 \mathrm{~km}^{2}$. As mentioned previously, to date, these analyses have focused on individual landslides or small areas. After the orientation of LiDAR data and images downloaded from public data servers, DSMs, orthophotographs and DoDs were obtained, which allowed the identification of vertical changes in the ground surface. To discriminate landslides from other possible causes of changes in the surface, a series of filters was applied (mask of vegetation, water and urban areas, mean filter and height differences threshold), in addition to the photointerpretation of the images themselves. Once the landslide inventory had been obtained, morphometric and factor analyses were conducted in order to characterize the landslide type, morphology and activity. Moreover, a set of common landslide areas was used in addition to the inventory to monitor the landslide activity. Finally, this landslide activity was correlated with rainfall as the main triggering factor of instability in the study area. 


\section{Materials and Methods}

\subsection{Study Area}

The study area of $51.4 \mathrm{~km}^{2}$ is located south of the city of Jaén, in the vicinity of the A-44 highway that connects it with Granada along the Guadalbullón river valley. The hillslopes, where the highway cuts are developed, have a moderate to high slope angle. There are numerous instability processes that usually correspond to slides and flows and even rock falls to a lesser extent [35-37], according to the Varnes classification [38,39] (Figures 1 and 2).
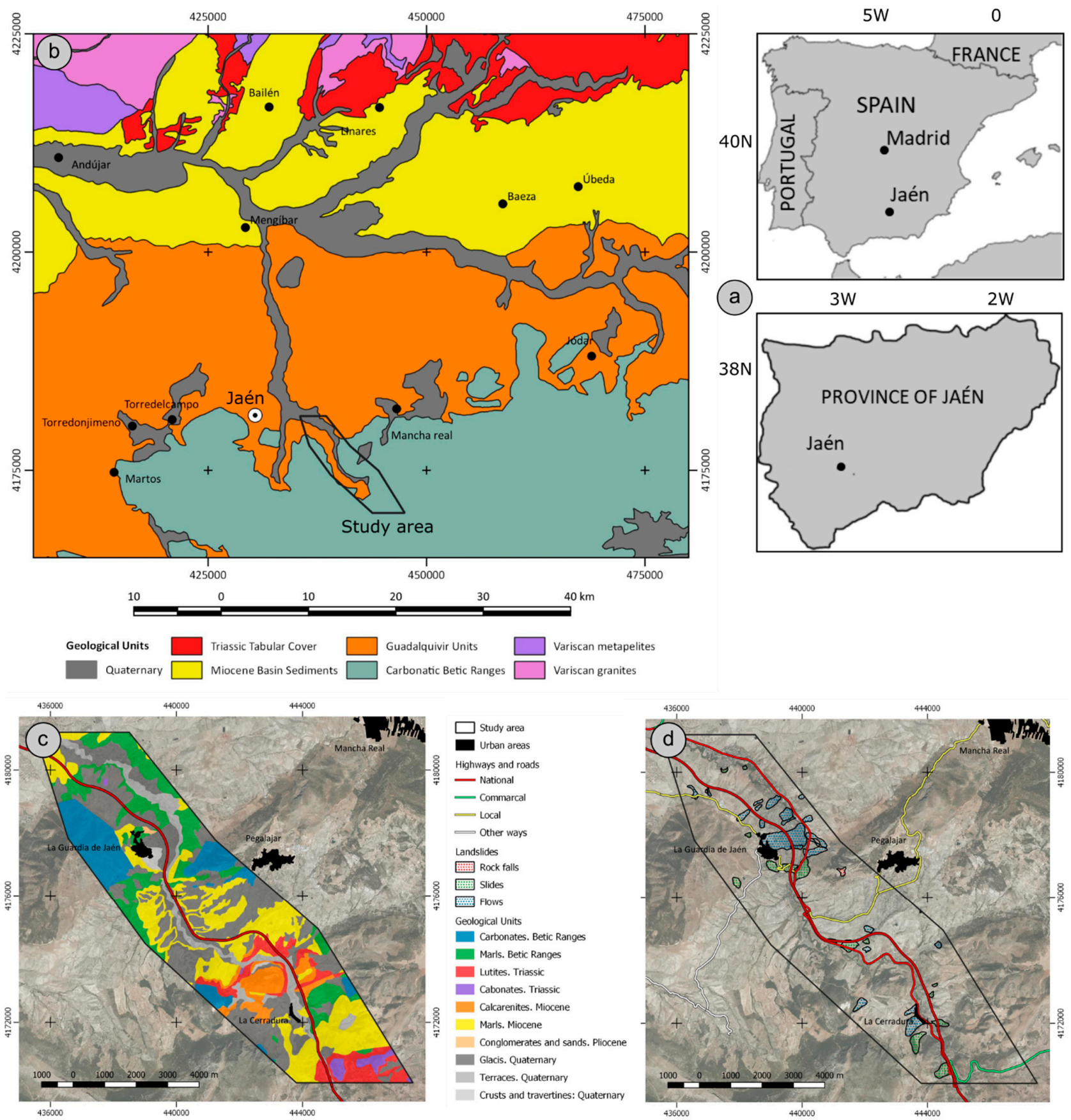

Figure 1. Geographical location and geological setting of the study area: (a) geographical location; (b) geological setting; (c) geological units in the study area; (d) landslide inventory. Coordinates are in ETRS89-UTM30. 


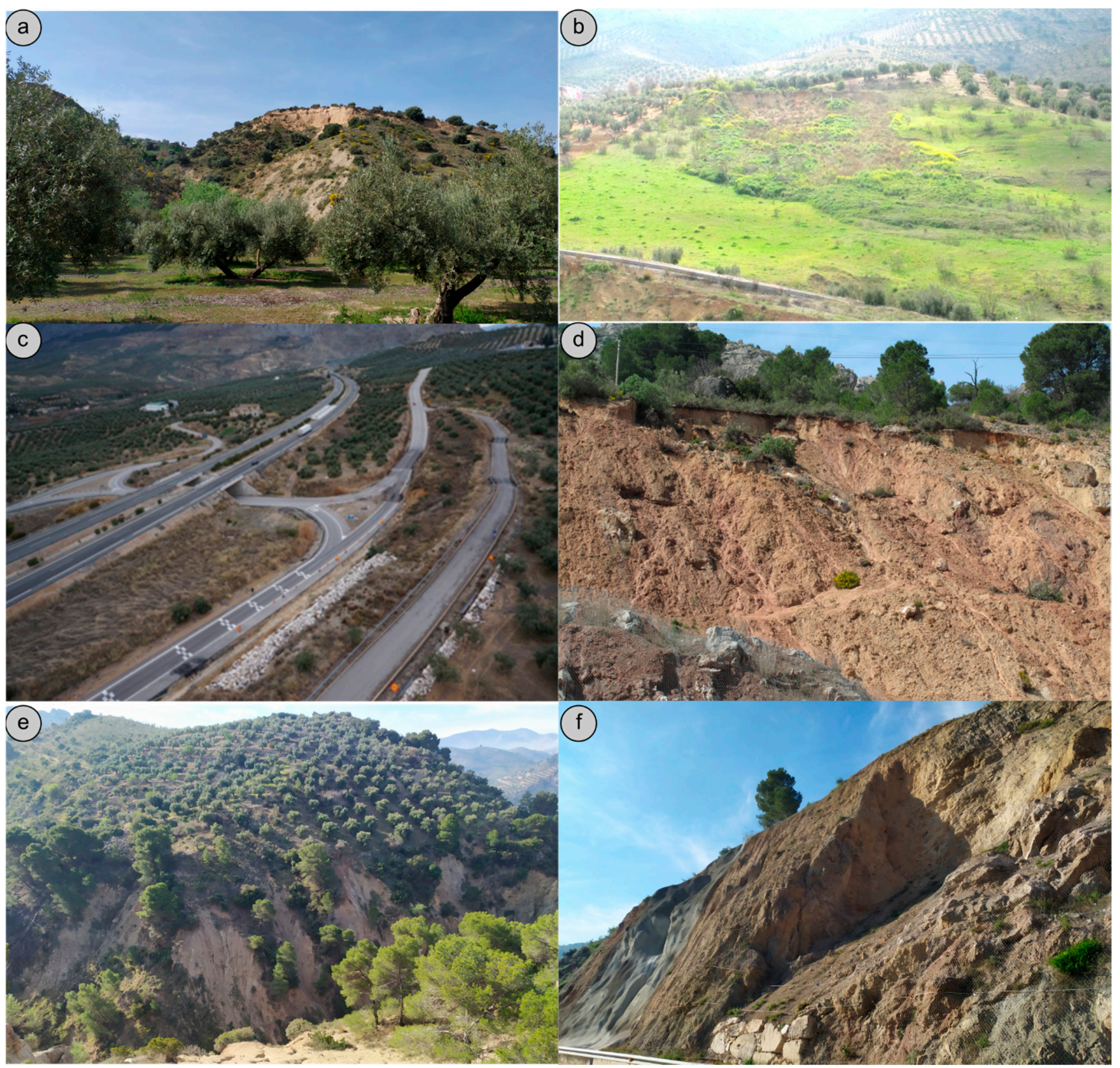

Figure 2. Examples of landslides in the study area: (a) collapses and slides in the area 1 ; (b) flow in the area 3; (c) foot of a flow in area 4 affecting roads; (d) slide in area 9; (e) natural collapses in area 9; (f) collapses in engineering slopes in area 10.

In the area, diverse materials appear, belonging to different tectonic [40] units of a complex and widely discussed structure (Figure 1):

- Triassic materials, consisting of clays, shales, carbonates and evaporites;

- Middle Subbetic, formed by thick carbonated series (Jurassic) overlayed by marls and marly limestones (Cretaceous);

- Intermediate Units, where the previous series are repeated with variations;

- Prebetic, in which marls, marly limestones, limestones and dolomites (Cretaceous) outcrop;

- Guadalquivir Units, where different materials predominate: evaporite and shale sections (Triassic), loams and clays (Cretaceous-Paleogene) and marly clayey sediments (Lower Miocene) [41];

- Pliocene conglomerates and sands;

- Quaternary fillings (colluvial and alluvial materials, debris, terraces and soils). 


\subsection{Materials}

Our methodology focuses on the combined use of aerial photogrammetry and LiDAR techniques, with data captured from conventional aerial platforms with decametric resolution. First, an ad hoc combined flight, with a digital camera (Z/I DMC) and LiDAR sensor (Leica ALS50-II), was flown in 2010 with GNSS/inertial measurement unit (IMU) systems for direct georeferencing and flight guidance. The aerial images have four radiometric bands (RGB and near infrared (NIR)), and the ground sample distance (GSD) of the images is $0.20 \mathrm{~m}$ (Table 1). Meanwhile, the LiDAR resolution is about $1-1.5$ points $/ \mathrm{m}^{2}$. Initially, this flight was planned to study the instability processes along the A-44 highway cuts, so several strips were flown along the length of the highway (Figure 1).

Table 1. Properties of the aerial images and LiDAR data sets.

\begin{tabular}{|c|c|c|c|c|c|c|}
\hline \multicolumn{7}{|c|}{ Aerial Image Properties } \\
\hline Date & Bands & Format & Scale & Camera & $\begin{array}{c}\text { Digitalization Resolution } \\
\text { (mm) }\end{array}$ & $\begin{array}{l}\text { GSD } \\
(\mathrm{m})\end{array}$ \\
\hline 1984 & Panchromatic & Film & $1: 30,000$ & Wild RC10 & 0.025 & 0.75 \\
\hline 1996 & Panchromatic & Film & $1: 20,000$ & Wild RC10 & 0.020 & 0.30 \\
\hline 2001 & Panchromatic & Film & $1: 20,000$ & Leica RC30 & 0.015 & 0.30 \\
\hline 2005 & CIR & Film & $1: 30,000$ & Leica RC30 & 0.015 & 0.45 \\
\hline 2009 & RGB & Digital & $1: 30,000$ & Z/I DMC120 & - & 0.45 \\
\hline $2010^{1}$ & RGB-NIR & Digital & $1: 10,000$ & Z/I DMC & - & 0.20 \\
\hline 2011 & RGB & Digital & $1: 30,000$ & Z/I DMC120 & - & 0.45 \\
\hline 2013 & RGB & Digital & $1: 30,000$ & Vexcel UCXp & - & 0.45 \\
\hline 2016 & RGB-NIR & Digital & $1: 30,000$ & Vexcel UCXp & - & 0.45 \\
\hline \multicolumn{7}{|c|}{ LiDAR dataset } \\
\hline Date & \multicolumn{4}{|c|}{ System } & \multicolumn{2}{|l|}{ Points $/ \mathrm{m}^{2}$} \\
\hline 2010 & \multicolumn{4}{|c|}{ Leica ALS50-II } & \multicolumn{2}{|l|}{$1-1.5$} \\
\hline
\end{tabular}

Furthermore, a set of conventional aerial surveys from 1984 (National Geographic Institute of Spain, IGN); 1996 and 2001 (Andalusian Institute of Statistics and Cartography, IECA); and 2005, 2009, 2011, 2013 and 2016 (National Plan of Aerial Orthophotography, PNOA) was also processed (Table 1). All data are available in different image formats (TIFF/JPG/ECW) from public spatial data infrastructures (SDIs) or data servers, such as the photo library of the IGN [42] and the photo library of Andalusia [43]. The image ground sample distance (GSD) of the different flights varies from 0.20 (in 2010) to $0.75 \mathrm{~m}$ (in 1984), although the GSD of most flights ranges between 0.30 and $0.45 \mathrm{~m}$. The 1984, 1996, 2001 and 2005 flights are analog (film-based cameras): the 2005 flight is color infrared (CIR), while the 1984, 1996 and 2001 flights are panchromatic. Original film images were digitized at different scanning resolutions between 1000 and 1700 ppi, which implied different image pixel sizes of $0.015-0.025 \mathrm{~mm}$. The remaining flights are digital and available as color, RGB (2009, 2011 and 2013), and color-near infrared, RGB-NIR (2016).

\subsection{Methodology}

The methodology consists of several phases partially described in previous studies $[10,16,21,24,44,45]$, which can be summarized in the following steps (Figure 3):

1. Orientation of the 2010 reference flight (photogrammetric and LiDAR).

2. Orientation of the remaining flights in the same coordinate reference system as the reference flight.

3. Generation of the DSMs and orthophotographs.

4. Calculation of differential DSMs (DoDs).

5. Filtering and masking of DoDs.

6. Elaboration of the multitemporal landslide inventory. 


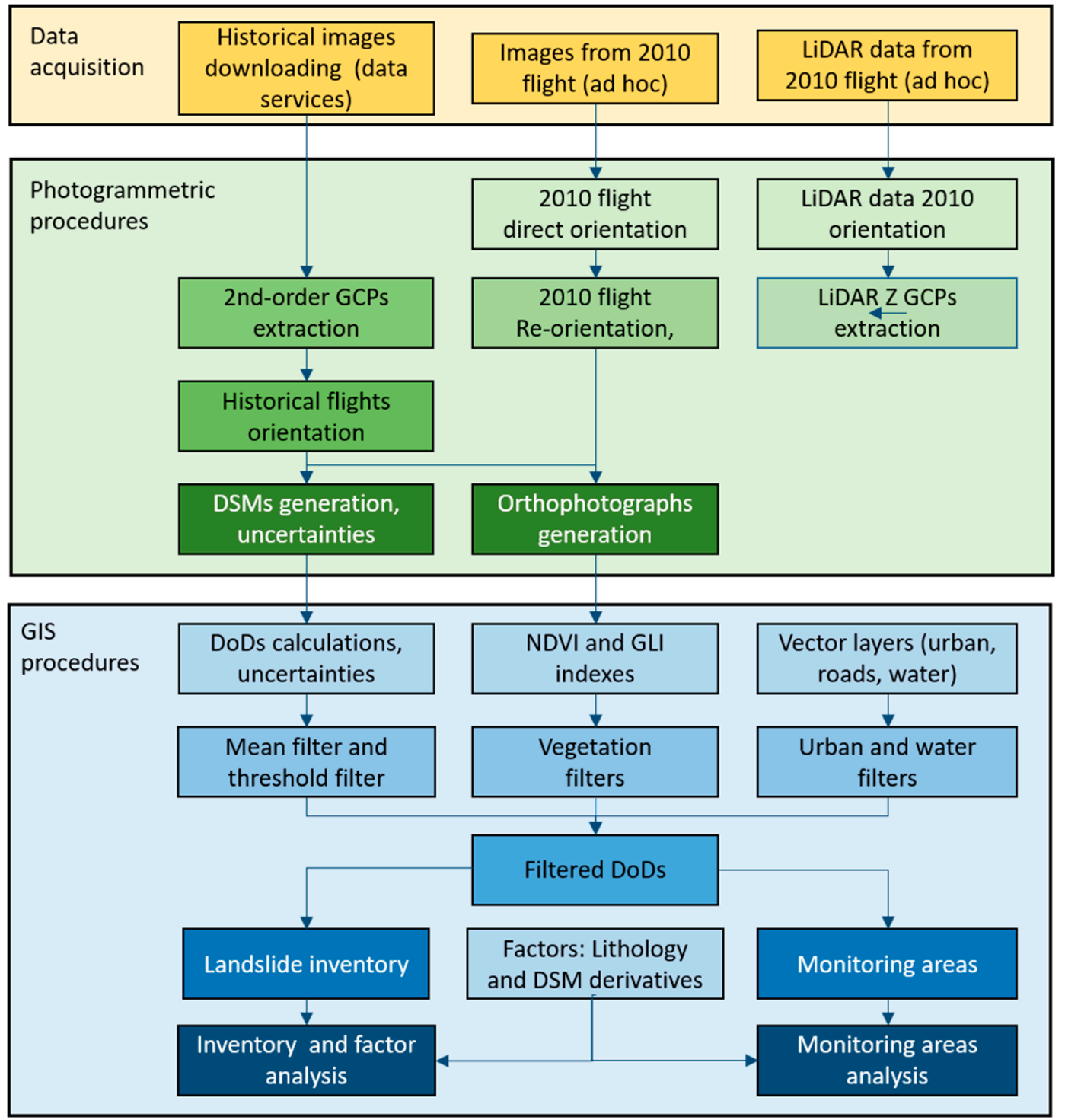

Figure 3. Methodology workflow.

\subsubsection{Orientation of the Reference Flight}

First, the reference 2010 flight was processed by means of direct orientation techniques based on the flight parameters (GNSS and IMU data) in the digital photogrammetric workstation (DPW) and the software Socet Set 5.6 [46]. The reference coordinate system was ETRS89 UTM 30N (EPSG: 25830).

After the first orientation step, some residual misalignment between the photogrammetric and LiDAR data persisted, despite the simultaneity of the acquisition process of both data sets. In this case, the photogrammetric flight was finely aligned, using a set of 25 height ground control points (Z GCPs) extracted from the LiDAR point cloud following the methodology developed in $[44,45]$. Table 2 shows the results of this fine adjustment. Thus, the errors of the photogrammetric orientation of the $2010 \mathrm{flight}$, expressed as the root mean square (RMS), were 0.030 and $0.093 \mathrm{~m}$ for $\mathrm{XY}$ and Z, respectively. 
Table 2. Orientation errors.

\begin{tabular}{|c|c|c|c|c|c|c|c|c|}
\hline \multirow{2}{*}{ Date } & \multirow{2}{*}{$\begin{array}{l}\text { Number of } \\
\text { Photographs }\end{array}$} & \multirow{2}{*}{$\begin{array}{c}\text { GCP-Type } \\
\text { Number }\end{array}$} & \multirow{2}{*}{$\begin{array}{c}\text { Tie Points } \\
\text { Number }\end{array}$} & \multirow{2}{*}{$\begin{array}{l}\text { RMS } \\
\text { (Pixel) }\end{array}$} & \multicolumn{2}{|c|}{ RMS GCP Error (m) } & \multicolumn{2}{|c|}{ RMS Prop. Error (m) } \\
\hline & & & & & $\mathrm{RMS}_{\mathrm{XY}}$ & $\mathbf{R M S}_{\mathrm{Z}}$ & $\mathrm{RMS}_{\mathrm{XY}}$ & $\mathrm{RMS}_{\mathrm{Z}}$ \\
\hline 1984 & 30 & $28 x y z, 26 z$ & 162 & 0.507 & 0.266 & 0.084 & 0.268 & 0.125 \\
\hline 1996 & 38 & 20 xyz & 178 & 0.474 & 0.172 & 0.136 & 0.175 & 0.165 \\
\hline 2001 & 32 & $9 x y z$ & 140 & 0.571 & 0.067 & 0.093 & 0.073 & 0.132 \\
\hline 2005 & 32 & $11 x y z, 19 z$ & 164 & 0.637 & 0.049 & 0.133 & 0.057 & 0.162 \\
\hline 2009 & 33 & $15 x y z, 9 z$ & 186 & 0.506 & 0.027 & 0.200 & 0.040 & 0.221 \\
\hline $2010^{1}$ & 98 & $25 \mathrm{z}$ & 649 & 0.328 & 0.030 & 0.093 & - & - \\
\hline 2011 & 35 & $33 x y z, 17 z$ & 201 & 0.376 & 0.139 & 0.110 & 0.142 & 0.144 \\
\hline 2013 & 31 & $27 x y z$ & 211 & 0.570 & 0.068 & 0.044 & 0.074 & 0.103 \\
\hline 2016 & 22 & $16 x y z$ & 122 & 0.604 & 0.052 & 0.035 & 0.060 & 0.099 \\
\hline
\end{tabular}

${ }^{1}$ Reference flight. ${ }^{2}$ GCP-type: xyz: full GCP; z: height GCP.

\subsubsection{Orientation of the Remaining Flights}

Next, the previous historical flights (1984, 1996, 2001, 2005 and 2009) and subsequent flights (2011, 2013 and 2016) were oriented according to a similar methodology used by authors in previous studies $[10,16,44,45]$, where second-order GCPs located in stable areas were transferred from the 2010 reference flight. This procedure ensures that all flights are oriented in the same coordinate reference system as the 2010 reference flight. Furthermore, this approach implies that there is no requirement of field-surveyed GCP. Table 2 shows the number and properties of the GCPs for each flight.

As the second-order GCPs are directly located on the photogrammetric flights on the DPW, it is possible to ensure in real time whether the point is observable and unequivocally recognizable on both flights. Moreover, transferring GCPs to historical flights facilitates the location of these GCPs when the landscape has dramatically changed, and it is sometimes almost impossible to identify suitable present points in the field from old aerial images. The theoretical reduction in accuracy with the use of the second-order GCP is considered negligible, as a photogrammetric flight with higher resolution and a low RMS error (lower than the GSD of all flights) was used as a reference [16]. Thus, the accuracy estimated in the transferred GCPs was proven to be better than the resolution of the historical flights.

Table 2 also shows the results of this process, expressing the RMS of the orientation residual errors. Thus, horizontal RMS ${ }_{X Y}$ errors ranged from values equal to or lower than $0.10 \mathrm{~m}$ in most flights, about $0.15 \mathrm{~m}$ in the 1996 and 2011 flights and $0.27 \mathrm{~m}$ in the 1984 flight. RMS $\mathrm{z}$ errors were also lower than or equal to $0.10 \mathrm{~m}$ in most flights, $0.13-0.14 \mathrm{~m}$ in the 1996 and 2005 flights and $0.20 \mathrm{~m}$ in the 2009 flight.

However, as the historical flights were oriented using transferred GCPs obtained from the reference 2010 flight, the precision of any measurement in those flights is influenced by the error propagation from the reference flight. Therefore, the propagated error (RMS Prop) of these flights can be calculated according to the following expression:

$$
\text { RMS Prop YEAR }=\left(\mathrm{RMS}_{2010}{ }^{2}+\mathrm{RMS}_{\mathrm{YEAR}}{ }^{2}\right)^{0.5}
$$

Thus, RMS ${ }_{X Y}$ errors were very similar to the previous ones, since the error of the 2010 flight was very small, and thus they ranged from around $0.05 \mathrm{~m}$ to 0.27 . Meanwhile, $\mathrm{RMS}_{Z}$ errors ranged between 0.10 and $0.22 \mathrm{~m}$.

\subsubsection{Generation of the DSMs and Orthophotographs}

After the orientation of all the flights, automatic image correlation (dense matching) and differential rectification techniques were used to generate the digital surface models (DSMs) and orthophotographs for every epoch, using the Next Generation Automated Terrain Extraction (NGATE) module of Socet Set $5.6[46,47]$. A DSM resolution of 5 times $(2.5 \mathrm{~m})$ the value of the original imagery GSD $(0.5 \mathrm{~m})$ was considered, following the conventional usage in photogrammetry of applying a multiple value of the GSD for DSM generation, which is gradually being reduced thanks to the improvement of algorithms for 
the automatic measurement of points. The GSD considered for the orthoimage generation is equal to the original imagery GSD $(0.5 \mathrm{~m})$. Finally, both the DSMs and orthophotographs were exported to a raster format (TIFF) in order to be used in the GIS software.

As shown in previous studies $[11,16,45]$, the vertical uncertainties in DEMs obtained by means of image-matching in photogrammetric flights were about two to three times the RMS propagated errors in Z. Therefore, the vertical uncertainties of DSMs obtained in this study ranged from $0.23 \mathrm{~m}$ for the 2010 reference flight to $0.25-0.40 \mathrm{~m}$ for most flights and $0.55 \mathrm{~m}$ for the 2009 flight (Table 3).

Table 3. Uncertainties in DSMs and DoDs.

\begin{tabular}{ccccc}
\hline Date & Z Propag. Error $(\mathbf{m})$ & Uncert. in DSMs $(\mathbf{m})$ & Period & Uncert. in DoDs (m) \\
\hline 1984 & 0.125 & 0.313 & & \\
1996 & 0.165 & 0.413 & $1984-1996$ & 0.518 \\
2001 & 0.132 & 0.330 & $1996-2001$ & 0.528 \\
2005 & 0.162 & 0.405 & $2001-2005$ & 0.522 \\
2009 & 0.221 & 0.553 & $2005-2009$ & 0.685 \\
2010 & 0.093 & 0.233 & $2009-2010$ & 0.599 \\
2011 & 0.144 & 0.360 & $2010-2011$ & 0.429 \\
2013 & 0.103 & 0.258 & $2011-2013$ & 0.443 \\
2016 & 0.099 & 0.248 & $2013-2016$ & 0.357 \\
\hline
\end{tabular}

\subsubsection{Calculation of Differential DSMs (DoDs)}

DSMs of differences (DoDs) were calculated from the DSMs of the successive dates by means of the free and open GIS software, QGIS [48]. These models allow the objective characterization of areas that show significant vertical changes in the ground surface or height differences between consecutive models. These height differences may be negative or positive, depending on whether each model lies below or above the preceding one, which would allow the identification of landslide areas with ground ascent (mass depletion) or descent (mass accumulation), respectively.

Unlike other studies [16,31], in this paper, DSMs were used instead of DTMs, because the models are of photogrammetric origin without stereo edition. Therefore, the processes of automatic classification and filtering of point clouds do not ensure accurate results in areas where there is a dense vegetation cover or other elements. Moreover, the stereo edition of models with a DPW to obtain DTMs in a wide area would be extremely timeconsuming. However, this produces a distortion in the landslide detection because some height differences can be caused by vegetation (growing, clearing, etc.), construction or other elements included in the DSMs, which requires some filtering operations, which are discussed in the following sections.

Regarding the vertical uncertainties of the DoDs, they were estimated as follows $[11,27,32,49]$ :

$$
\text { Unc.YEAR1-YEAR2 }=\left(\text { Unc. YEAR1 }^{2}+\text { Unc. YEAR2 }^{2}\right)^{0.5}
$$

Thus, the uncertainty of the differential DSMs ranged from 0.35 to $0.70 \mathrm{~m}$, being generally lower in the comparison of more recent flights and higher in the comparison of older flights (Table 3).

\subsubsection{Filtering and Masking of DoDs}

Once the differential models were obtained, it was necessary to identify the unstable areas or landslides, since not all the vertical changes measured in the DoDs were due to landslides. In fact, these were also due to vegetation changes, new constructions, maintenance work, etc., as mentioned previously. In addition, there was noise due to residual image misalignments and inaccuracies in DSM generation.

Thus, as the manual stereo edition of DSMs was discarded, other solutions were addressed based on the application of filters and masks in order to identify landslides from 
the DoDs. First, vegetation indexes, such as the normalized difference vegetation index (NDVI), were calculated from orthophotographs available in Spanish and Andalusian spatial data infrastructure [50]. These indexes allowed the exclusion of areas with dense vegetation by establishing threshold values. The NDVI [51] was calculated from the following expression:

$$
\mathrm{NDVI}=(\mathrm{R}-\mathrm{NIR}) /(\mathrm{R}+\mathrm{NIR})
$$

being $R$ and NIR the Digital Number (DN) in the red and NIR bands.

Nevertheless, since the original photographs did not have true reflectance values, only digital numbers (DN) resulting from the data processing, the NDVI showed relative and approximate values. Moreover, only the photographs of the 2010 flight (reference) as well as the 2016 and 2005 flights-as they are available in the SDI_include an NIR band. Specifically, the images of 2016 and 2010 present four bands: blue, green, red and NIR; the images of 2005 present three bands: green, red and NIR. Then, other indexes, based only on visible bands, were considered for RGB images (2013, 2011 and 2009), such as the Green Leaf Index (GLI) [52], which could be calculated with the following expression:

$$
\mathrm{GLI}=((\mathrm{G}-\mathrm{R})+(\mathrm{G}-\mathrm{B})) /(2 \mathrm{G}+\mathrm{R}+\mathrm{B}),
$$

where $\mathrm{R}, \mathrm{G}$ and $\mathrm{B}$ are the $\mathrm{DN}$ in the corresponding RGB bands.

Finally, the older images corresponding to the 1984, 1996 and 2001 aerial surveys are panchromatic, so it was not possible to obtain vegetation indexes for these.

The index images were then classified by means of different thresholds, and several masks were obtained and applied to the DoDs. For the relative NDVI estimated, the threshold was fixed at 0.4, analyzing the images and their histograms in order to discriminate between vegetated and non-vegetated areas. This value allowed us to separate trees (pines, oaks, riparian, olives, etc.) from soil, water and urbanized areas, but also from brush and grass. Since all the flights were performed during the summertime, which is usually very dry in Southern Spain, these last covers present lower NDVI values. Meanwhile, for GLI, the threshold was fixed at 0.05 , in accordance with the strategy described previously, which also separated trees from the other land covers. Finally, the panchromatic images did not allow us to establish a threshold to distinguish vegetated areas from other land cover, such as soils, urban and water. These masks, resulting from the binarization of NDVI and GLI images, were then filtered by means of a mode filter in order to obtain continuous masks. The window size of this filter was large enough $(21 \times 21$ pixels, corresponding to $10.5 \times 10.5 \mathrm{~m}$ ) to filter the olive trees, which were integrated in the soil, but it allowed the exclusion of densely vegetated areas, especially those made up of trees (pines, oaks and riparian). Since the vegetated areas were changing from year to year and, in addition, there were no masks for some years (panchromatic images), a unique vegetation mask was generated. The final mask was obtained with the global extension of all the individual masks, and then filtered again with the same filter $(21 \times 21$ mode $)$. Afterwards the filter mask was resampled to a pixel size of $2.5 \mathrm{~m}$, the same as the DoDs. The process of this vegetation filter is shown in Figure 4. 


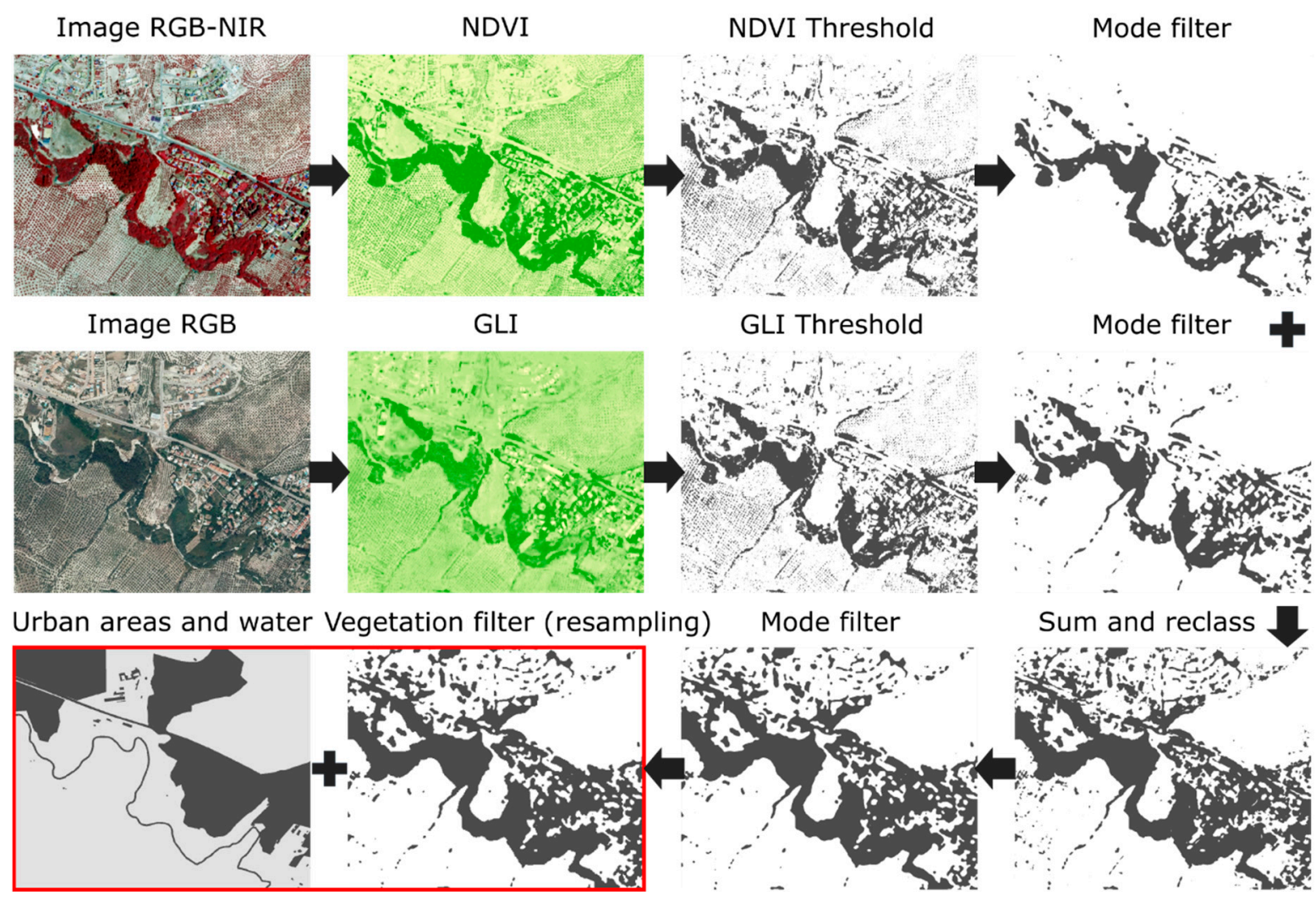

Figure 4. Detail of the process employed to obtain vegetation, urban and water filters. False color composition of image RGB-NIR is NIR-Red-Green. Final applied filters are highlighted in red.

Then, a second mask with urban areas (populations, industrial, isolated buildings, roads, constructions, etc.) and water bodies (river and wetlands) was applied. These new masks were obtained from vector layers (shape files) downloaded from the Andalusian $\mathrm{SDI}$ and then rasterized to a resolution of $2.5 \mathrm{~m}$ and applied to the DoDs. Thus, urban and water areas, the same as the vegetated areas, were discarded as potential areas of landslides. This filter is also shown in Figure 4.

Third, a new convolution mean filter in a $5 \times 5$ pixel window $(12.5 \times 12.5 \mathrm{~m})$ was applied again to the DoDs in an iterative manner in order to eliminate or reduce the noise caused by local residual misalignments in the orientation process, propagated to DSMs and DoDs, as well as the remains of the vegetation and other elements.

Finally, based on the uncertainty of the DoDs, another filter was applied in order to discard those areas with height differences with an absolute value lower than $1 \mathrm{~m}$ and also to reduce noise. In this sense, since, in this study, DoDs were only used for detecting unstable areas and estimating their activity but not for quantifying volumes, more complete approaches were not considered $[49,53]$.

\subsubsection{Elaboration of the Multitemporal Landslide Inventory}

The final step in elaborating the landslide inventory and database was the photointerpretation and digitalization on orthophotographs and DoDs for each date and period. The most common method for identifying and delineating landslides is photointerpretation, both in 2D from orthophotographs and in 3D using analog stereoscopes or digital photogrammetric stations $[3,4]$. However, the process is relatively cumbersome, especially when a multitemporal approach is required, and subjective; thus, some movements frequently remain undetected to inexpert photointerpreters [4].

In this case, once the DoD calculation and filtering had been carried out, the results were checked using photointerpretation techniques in orthoimages and stereo pairs. This photointerpretation was performed considering the areas in which the estimated differ- 
ences were higher than the estimated propagated uncertainty ( $1 \mathrm{~m}$ in absolute terms). This allowed for discrimination between landslides and other objects (DSM artefacts and misalignments), as well as true changes in the terrain itself, such as vegetation, constructions, excavations, fillings and quarries, not detected in the previous analysis. A useful criterion for identifying movements was the detection of adjacent areas of descent (or depletion) and ascent (or accumulation), the first area being topographically higher than the latter one [31].

Once the landslides had been identified, they were digitized in the GIS, obtaining different vector layers for each date. Then, different analyses were performed to characterize the movements and to complete the database with landslide typology, morphometric parameters, lithology, activity, etc. Landslide typology was assigned based on the height differences calculated in the DoDs and the length of the estimated movements, according to the well-known landslide classifications after Varnes [38,39], but it was also based on photointerpretation. Morphometric parameters, such as landslide areas $(\mathrm{A})$, perimeters $(\mathrm{P})$, height interval or range $(\mathrm{H})$, length $(\mathrm{L})$ and $\mathrm{H} / \mathrm{L}$ ratio [54], were calculated by means of different tools (geometric, arithmetic, zonal, etc.) of QGIS software, based on the inventory vector layers and the DSMs. In the same way, landslide conditions (average height, slope and orientation, as well as modal lithology) were also obtained in the GIS from the inventory, DSMs, the slope and orientation maps, as well as the lithological units derived from the geological map [40].

Regarding the activity, this could be estimated from the zonal analysis of the inventory on the DoDs. However, since the inventory is more oriented towards landslide characterization, another approach was used which is the analysis of monitoring areas. Thus, the activity of some representative examples of landslide monitoring areas with different characteristics (geological, topographical and landslide typology) was evaluated by means of the zonal analysis of filtered DoDs. This approach allowed the estimation of average height differences in the monitoring areas for the different periods, resulting in negative or positive balances that corresponded to general descents or ascents of the ground surface in these areas. Considering only the sectors of filtered DoDs with negative values or positive values, the average descents or ascents of the ground surface were also calculated. Dividing the height differences by the period length, the average vertical velocity could be estimated, although more accurate calculations of the velocity (vertical and horizontal) would require the measurement of displacements of points sampled in the unstable area [21,24]. Nevertheless, this estimated vertical velocity allowed the characterization of the activity of the landslide monitoring areas, according to published classifications $[55,56]$ throughout the different periods, which could be related to the rainfall regime as the main triggering factor of landslides.

\section{Results}

The filtered DoD maps were the first results of this study from which a multitemporal landslide inventory was obtained. In this section, this inventory is presented in order to characterize and analyze the landslides of the study area. Moreover, a set of monitoring areas was also analyzed in order to determine the landslide activity of this area.

\subsection{Analysis of the Multitemporal Landslide Inventory}

Figure 5 shows the inventory differenced by periods, and Table 5 displays the corresponding analysis. Three basic landslide typologies were identified: falls-collapses, slides and flows [38,39]. In general terms, landslides cover $0.98 \mathrm{~km}^{2}$, representing $1.90 \%$ of the study area. In the first class, rock falls and collapses, only one rock fall in the strict sense was identified. Moreover, collapses in natural and engineering slopes were distinguished. Natural collapses extended for $0.46 \mathrm{~km}^{2}(46.63 \%$ of the landslide area), collapses in engineering slopes extended for $0.16 \mathrm{~km}^{2}(16.57 \%)$, slides extended for $0.24 \mathrm{~km}^{2}(25.00 \%)$ and flows extended for $0.11 \mathrm{~km}^{2}(11.78 \%)$. Average areas ranged from about $1000 \mathrm{~m}^{2}$ of collapses (both natural and engineering slopes), to nearly $4500 \mathrm{~m}^{2}$ of slides and $10,800 \mathrm{~m}^{2}$ 
of flows. The height interval had an average value of about $20 \mathrm{~m}$, ranging from 15 to $19 \mathrm{~m}$ in collapses to around $40 \mathrm{~m}$ in slides, flows and rock falls. The average H/D ratio was 0.48 , ranging from 0.19 in flows and $0.5-0.6$ in slides and collapses to 2.23 in rock falls.

a

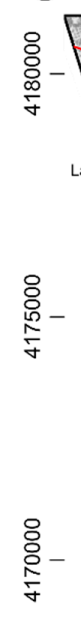

(d) (b) 440000

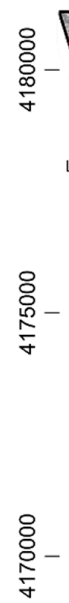
(g)
T.> $1984-1996$

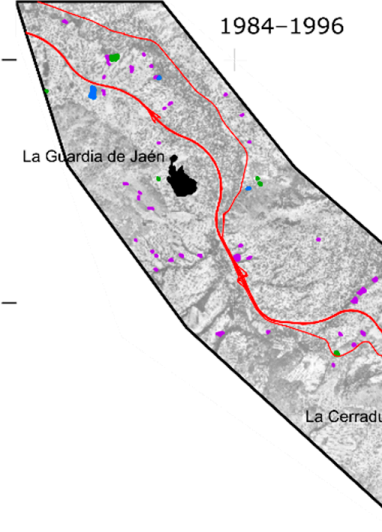

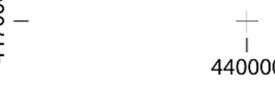

$\frac{T}{1}$
440000
440000

(e)

(h) $\quad 440000$

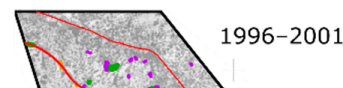

(c)

440000

445000
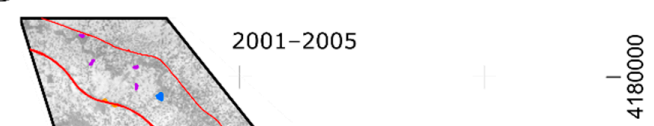

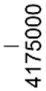

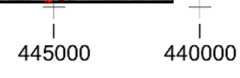

440000
1

(f)
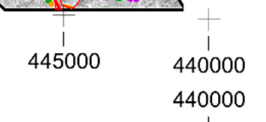

$\quad 445000$
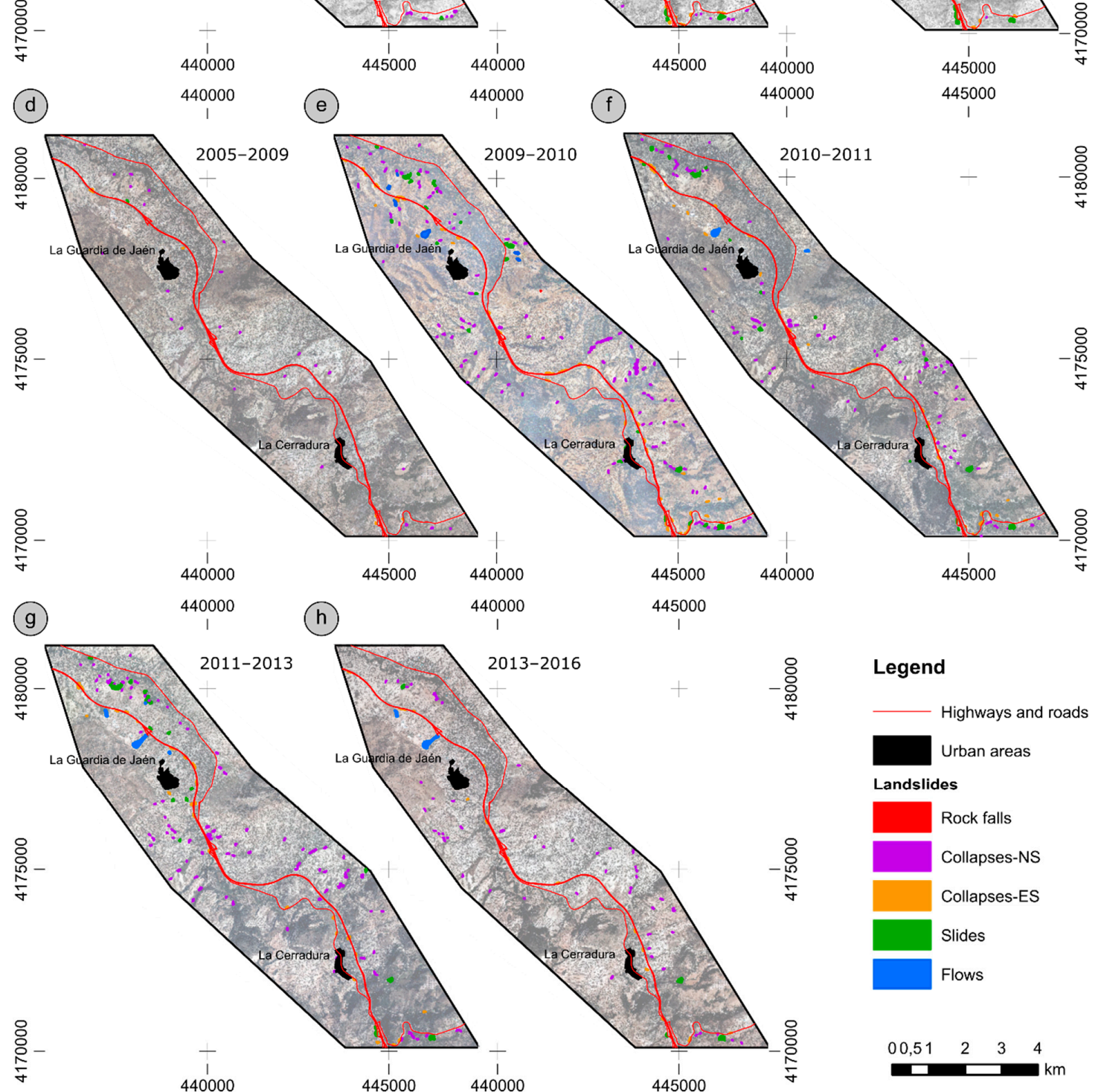

$\underset{\text { | }}{44000}$
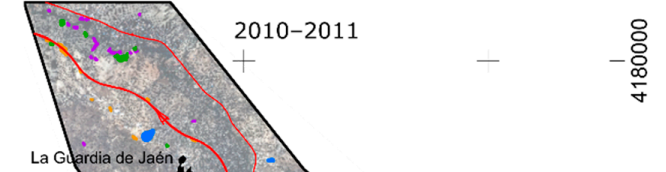

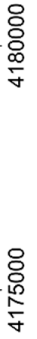

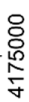

Figure 5. Multitemporal landslide inventory: (a) 1984-1996; (b) 1996-2001; (c) 2001-2005; (d) 2005-2009; (e) 2009-2010; (f) 2010-2011; (g) 2011-2013; (h) 2013-2016. Collapses in natural slopes (NS) and in engineering slopes (ES). Coordinates are found in ETRS89-UTM30. 
Table 4. Analysis of the multitemporal landslide inventory.

\begin{tabular}{|c|c|c|c|c|c|c|c|c|c|c|c|c|c|c|}
\hline Date & Typol. & $\mathrm{N}^{\mathbf{o}}$ & $\% \mathrm{~N}$ & Tot.Area $^{1}$ & $\%$ TA & Area $^{1}$ & Perim. $^{2}$ & H. Int. ${ }^{2}$ & $\mathrm{H} / \mathrm{L}$ & Height $^{2}$ & Slope ${ }^{3}$ & Orien. $^{3}$ & $\mathrm{DoD}^{2}$ & Lithol. \\
\hline \multirow{6}{*}{$\begin{array}{c}1984 \\
- \\
1996\end{array}$} & R. Falls & 0 & 0.00 & - & - & - & - & - & - & - & - & - & - & - \\
\hline & Col-NS & 66 & 80.49 & 107,819 & 69.22 & 1634 & 169 & 21.22 & 0.47 & 609 & 29.27 & 150 & -0.61 & 6 \\
\hline & Slides & 10 & 12.20 & 24,163 & 15.51 & 2416 & 179 & 26.80 & 0.48 & 528 & 23.31 & 355 & -0.54 & 2 \\
\hline & Flows & 3 & 3.66 & 20,097 & 12.90 & 6699 & 308 & 33.00 & 0.18 & 543 & 25.70 & 328 & 0.16 & 2 \\
\hline & Col-ES & 3 & 3.66 & 3678 & 2.36 & 1226 & 191 & 13.95 & 0.53 & 735 & 31.94 & 140 & -2.00 & 2 \\
\hline & Total & 82 & 100 & 155,757 & 100 & 1899 & 176 & 22.07 & 0.43 & 602 & 28.51 & 142 & -0.53 & 6 \\
\hline \multirow{6}{*}{$\begin{array}{c}1996 \\
- \\
2001\end{array}$} & R. Falls & 0 & 0.00 & - & - & - & - & - & - & - & - & - & - & - \\
\hline & Col-NS & 72 & 54.55 & 55.631 & 31.92 & 773 & 126 & 16.19 & 0.52 & 615 & 33.13 & 91 & -1.33 & 6 \\
\hline & Slides & 17 & 12.88 & 70,745 & 40.59 & 4065 & 242 & 26.83 & 0.37 & 569 & 23.00 & 101 & -0.96 & 2 \\
\hline & Flows & 5 & 3.79 & 20,850 & 11.96 & 4170 & 269 & 25.36 & 0.17 & 560 & 17.33 & 356 & -0.17 & 2 \\
\hline & Col-ES & 38 & 28.79 & 27,049 & 15.52 & 665 & 131 & 11.05 & 0.57 & 620 & 28.86 & 61 & -1.79 & 8 \\
\hline & Total & 132 & 100 & 174,275 & 100 & 1320 & 149 & 16.81 & 0.43 & 605 & 28.87 & 82 & -1.11 & 8 \\
\hline \multirow{5}{*}{$\begin{array}{c}2001 \\
- \\
2005\end{array}$} & R. Falls & 0 & 0.00 & - & - & - & - & - & - & - & - & - & - & - \\
\hline & Col-NS & 16 & 50.00 & 13,517 & 19.70 & 845 & 173 & 17.03 & 0.52 & 619 & 36.71 & 216 & -1.35 & 8 \\
\hline & Slides & 4 & 12.50 & 33,588 & 48.96 & 8397 & 403 & 48.26 & 0.47 & 677 & 31.24 & 77 & -0.13 & 3 \\
\hline & Flows & 1 & 3.13 & 7837 & 11.42 & 7837 & 365 & 28.29 & 0.14 & 509 & 15.01 & 68 & -0.13 & 2 \\
\hline & Col-ES & 11 & 34.38 & 13,663 & 19.92 & 1242 & 183 & 15.62 & 0.59 & 644 & 30.28 & 4 & -1.77 & 2 \\
\hline \multirow{6}{*}{$\begin{array}{c}2005 \\
- \\
2009\end{array}$} & R. Falls & 0 & 0.00 & - & - & - & - & - & - & - & - & - & - & - \\
\hline & Col-NS & 25 & 75.76 & 15,262 & 78.98 & 610 & 110 & 15.57 & 0.56 & 619 & 30.42 & 334 & -1.11 & 6 \\
\hline & Slides & 1 & 3.03 & 1398 & 7.23 & 1398 & 178 & 11.72 & 0.28 & 571 & 25.03 & 238 & -0.46 & 8 \\
\hline & Flows & 0 & 0.00 & - & - & - & - & - & - & - & - & - & - & - \\
\hline & Col-ES & 7 & 21.21 & 2664 & 13.79 & 381 & 115 & 9.40 & 0.64 & 598 & 26.48 & 34 & -1.20 & 2 \\
\hline & Total & 33 & 100 & 19,324 & 100 & 586 & 113 & 14.15 & 0.55 & 613 & 29.42 & 337 & -1.08 & 6 \\
\hline \multirow{6}{*}{$\begin{array}{c}2009 \\
- \\
2010\end{array}$} & R. Falls & 1 & 0.51 & 268 & 0.08 & 268 & 70 & 43.29 & 2.23 & 990 & 59.88 & 187 & -3.29 & 1 \\
\hline & Col-NS & 118 & 60.20 & 129,192 & 36.75 & 1095 & 158 & 18.65 & 0.50 & 628 & 29.75 & 315 & -1.38 & 6 \\
\hline & Slides & 26 & 13.27 & 113,848 & 32.39 & 4379 & 260 & 35.35 & 0.47 & 582 & 27.13 & 205 & -1.18 & 2 \\
\hline & Flows & 6 & 3.06 & 54,691 & 15.56 & 9115 & 361 & 39.27 & 0.18 & 583 & 21.44 & 53 & -0.25 & 2 \\
\hline & Col-ES & 45 & 22.96 & 53,525 & 15.23 & 1189 & 191 & 15.23 & 0.59 & 627 & 29.84 & 194 & -1.50 & 6 \\
\hline & Total & 196 & 100 & 351,524 & 100 & 1801 & 185 & 20.84 & 0.46 & 621 & 29.16 & 254 & -1.16 & 6 \\
\hline
\end{tabular}


Table 5. Cont.

\begin{tabular}{|c|c|c|c|c|c|c|c|c|c|c|c|c|c|c|}
\hline Date & Typol. & $\mathbf{N}^{\mathbf{0}}$ & $\% \mathbf{N}$ & Tot.Area ${ }^{1}$ & $\%$ TA & Area $^{1}$ & Perim. $^{2}$ & H. Int. ${ }^{2}$ & $\mathrm{H} / \mathrm{L}$ & Height $^{2}$ & Slope $^{3}$ & Orien. ${ }^{3}$ & $\mathrm{DoD}^{2}$ & Lithol. \\
\hline \multirow{5}{*}{$\begin{array}{c}2010 \\
- \\
2011\end{array}$} & R. Falls & 0 & 0.00 & - & - & - & - & - & - & - & - & - & - & - \\
\hline & Col-NS & 85 & 61.59 & 72,920 & 33.53 & 858 & 133 & 16.68 & 0.50 & 616 & 29.52 & 186 & -1.10 & 6 \\
\hline & Slides & 19 & 13.77 & 73,320 & 33.71 & 3859 & 225 & 27.23 & 0.39 & 586 & 23.42 & 195 & -1.37 & 6 \\
\hline & Col-ES & 32 & 23.19 & 36,135 & 16.62 & 1129 & 177 & 12.96 & 0.51 & 629 & 28.04 & 248 & -1.37 & 6 \\
\hline & Total & 138 & 100 & 217,475 & 100 & 1576 & 161 & 17.81 & 0.41 & 615 & 28.21 & 194 & -1.06 & 6 \\
\hline \multirow{6}{*}{$\begin{array}{c}2011 \\
- \\
2013\end{array}$} & R. Falls & 0 & 0.00 & - & - & - & - & - & - & - & - & - & - & - \\
\hline & Col-NS & 94 & 63.09 & 124,785 & 37.94 & 1327 & 160 & 20.26 & 0.49 & 594 & 28.75 & 331 & -1.33 & 6 \\
\hline & Slides & 22 & 14.77 & 106,383 & 32.35 & 4836 & 276 & 35.77 & 0.46 & 563 & 26.12 & 89 & -0.92 & 2 \\
\hline & Flows & 4 & 2.68 & 58,341 & 17.74 & 14,585 & 484 & 39.41 & 0.14 & 585 & 15.86 & 55 & -0.33 & 2 \\
\hline & Col-ES & 29 & 19.46 & 39,373 & 11.97 & 1358 & 178 & 17.54 & 0.63 & 592 & 28.61 & 53 & -1.79 & 8 \\
\hline & Total & 149 & 100 & 328,882 & 100.00 & 2207 & 190 & 22.54 & 0.44 & 589 & 27.99 & 37 & -1.08 & 6 \\
\hline \multirow{5}{*}{$\begin{array}{c}2013 \\
- \\
2016\end{array}$} & R. Falls & 0 & 0.00 & - & - & - & - & - & - & - & - & - & - & - \\
\hline & Col-NS & 52 & 70.27 & 43,096 & 30.05 & 829 & 134 & 18.12 & 0.56 & 637 & 32.19 & 184 & -1.48 & 6 \\
\hline & Slides & 4 & 5.41 & 36,132 & 25.20 & 9033 & 372 & 58.69 & 0.55 & 685 & 30.86 & 207 & -0.33 & 3 \\
\hline & Flows & 2 & 2.70 & 51,389 & 35.84 & 25,695 & 852 & 66.38 & 0.18 & 609 & 12.68 & 54 & 0.06 & 2 \\
\hline & Col-ES & 16 & 21.62 & 12,777 & 8.91 & 799 & 153 & 14.05 & 0.66 & 610 & 32.68 & 251 & -2.25 & 8 \\
\hline \multirow{6}{*}{$\begin{array}{c}1984 \\
- \\
2016\end{array}$} & R. Falls & 1 & 0.12 & 266 & 0.03 & 268 & 70 & 43.29 & 2.23 & 990 & 59.88 & 187 & -3.29 & 1 \\
\hline & Col-NS & 528 & 63.16 & 455,609 & 46.63 & 1065 & 147 & 18.84 & 0.51 & 614 & 30.11 & 264 & -1.18 & 6 \\
\hline & Slides & 103 & 12.32 & 244,193 & 24.99 & 4446 & 255 & 35.13 & 0.47 & 589 & 26.06 & 147 & -0.94 & 2 \\
\hline & Flows & 23 & 2.75 & 115,147 & 11.78 & 10,796 & 410 & 44.93 & 0.19 & 588 & 17.98 & 44 & -0.13 & 2 \\
\hline & Col-ES & 181 & 21.65 & 161,943 & 16.57 & 1034 & 167 & 14.55 & 0.60 & 621 & 29.32 & 176 & -1.65 & 8 \\
\hline & Total & 836 & 100 & 977,157 & 100.00 & 1747 & 172 & 20.32 & 0.48 & 610 & 29.09 & 104 & 0.00 & 6 \\
\hline
\end{tabular}

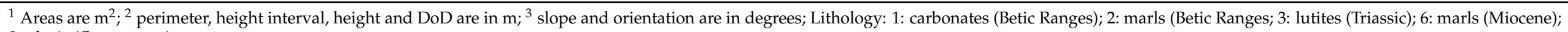
8: glacis (Quaternary). 
Regarding the average conditions in which landslides appear, the height was around $600 \mathrm{~m}$ in most cases and near $1000 \mathrm{~m}$ in the rock fall. The average slope was around $18^{\circ}$ in flows, while values of between 25 and $30^{\circ}$ occurred in slides and collapses (both in natural and engineering slopes), and $60^{\circ}$ in rock falls. Orientation is mostly towards the south and southeast, except collapses, which are mainly oriented to the west, and flows, which are oriented to the NE. Modal lithologies are Betic carbonates in the rock fall, Miocene marls in natural collapses, Betic marls from the Cretaceous age in slides and flows, and quaternary glacis and colluvial in collapses in engineering slopes. Finally, the average height differences between DSMs (DoDs) ranged from $-0.13 \mathrm{~m}$ in flows to $-0.94 \mathrm{~m}$ in slides, $-1.18 \mathrm{~m}$ in natural collapses, $-1.59 \mathrm{~m}$ in collapses in engineering slopes and $-3.29 \mathrm{~m}$ in rock falls.

Multitemporal analysis showed that the periods with higher activity were, in this order, 2009-2010, when the total area affected was of $0.35 \mathrm{~km}^{2}$ and there were 196 landslides, and 2011-2013 with $0.33 \mathrm{~km}^{2}$ and 149 landslides. Next, the periods 2010-2011 and 19962001 presented areas of 0.22 and $0.17 \mathrm{~km}^{2}$, respectively, and a number of landslides of 138 and $132 \mathrm{~m}$. The remaining periods, 1984-1996 (0.16 km² and 82 landslides), 2013-2016 $\left(0.14 \mathrm{~km}^{2}\right.$ and 74 landslides $)$ and especially $2001-2005\left(0.07 \mathrm{~km}^{2}\right.$ and 32 landslides $)$ and 2005-2009 (0.02 km² and 33 landslides), had lower activity. Landslides presented average areas ranging from about 1500 to $2000 \mathrm{~m}^{2}$ in most periods, except in 2005-2009 when the area was of around $600 \mathrm{~m}^{2}$. Average height intervals varied $\pm 5 \mathrm{~m}$ between the different periods, the largest variations being in slides (from $12 \mathrm{~m}$ in 2005-2009 to $59 \mathrm{~m}$ in 2013-2016) and flows (from 25-40 $\mathrm{m}$ in most periods to more than $50 \mathrm{~m}$ in 2010-2011 and 2013-2016). $\mathrm{H} / \mathrm{D}$ indexes were usually very uniform in general (0.4-0.5) for all typologies.

The conditions (height, slope, orientation and lithology) in which landslides appeared did not change significantly over the different periods. However, the average height differences ranged from values of $-0.53 \mathrm{~m}$ in the period $1984-1996$ to around $-0.70 \mathrm{~m}$ in the periods 2001-2005 and 2013-2016, to around $-1.00 \mathrm{~m}$ in the remaining periods (1996-2001, 2005-2009, 2009-2010, 2010-2011 and 2011-2013), usually the more active ones. All these values were negative, which implies a general descent of the ground surface.

\subsection{Analysis of Monitoring Areas}

As well as the multitemporal inventory, a set of common landslide areas throughout the whole period (1984-2016) was considered in order to monitor the landslide activity in the study area (Figure 6). Table 6 shows the results of this analysis, which was mainly focused on the rate of height differences between DSMs, both the average of the whole areas and the average of sectors with negative and positive values.

The most relevant results by areas are as follows:

- $\quad$ Area 1 (dominated by collapses and slides; Figure 7) showed some periods with significant rates of general ground descent in 2009-2010 and 2010-2011 (-0.30 and $-0.16 \mathrm{~m} /$ year, respectively). Sectors with descent rates reached high average rates in the periods 1996-2001, 2009-2010, 2010-2011 and 2011-2013 (0.5-4 m/year), while sectors with ascent rates did so in the period 2011-2013 (1.8 m/year).

- $\quad$ Area 2 (in which slides predominate) presented a general rate of ground descent in the period 2009-2010 (-0.21 m/year). The average descent rates were higher in 19962001 and 2009-2010 (0.4-1.6 m/year), with a significant ascent rate only in 1996-2001 (0.33 m/year).

- $\quad$ Area 3 (flows; Figure 8) showed a significant rate of general descent in the periods 20092010 and $2011-2013(-0.11$ and $-0.07 \mathrm{~m} /$ year $)$, with a great descent rate $(3.11 \mathrm{~m} /$ year $)$ and a moderate ascent rate (1.4 m/year) in 2009-2010.

- $\quad$ Area 4 (flows; Figure 8) showed only a certain general ground descent in the period 2011-2013 (-0.05 m/year), with moderate descent rates in 2009-2010, 2010-2011, 20112013 and 2013-2016 (0.5-1.3 m/year) and ascent rates in 2011-2013 and 2013-2016 (0.6-0.7 m/year). 
- Area 5 (slides) showed only a significant rate of general descent in the period 2009$2010(-0.17 \mathrm{~m} /$ year $)$, with a moderate descent rate $(1.68 \mathrm{~m} /$ year $)$ and ascent rate $(1.53 \mathrm{~m} /$ year $)$ in the same period.

- Area 6 (collapses) presented a rate of ground descent in the periods 2009-2010 and 2010-2011 ( -0.14 and $-0.05 \mathrm{~m} /$ year), with a significant descent rate in 2010-2011 (2.93 m/year) and ascent rate in 2011-2013 (1.48 m/year).

- Area 7 (collapses) showed a remarkable rate of general descent in 2009-2010 $(-0.42 \mathrm{~m} /$ year $)$, the descent rate being high in the same period $(2.57 \mathrm{~m} /$ year $)$ without significant ascent rates.

- Area 8 (collapses) also presented a great rate of general descent in the period 2009-2010 $(-0.45 \mathrm{~m} /$ year$)$, with a significant descent rate in the same period $(2.01 \mathrm{~m} /$ year $)$.

- Area 9 (collapses in engineering slopes; Figure 9) showed a significant rate of general descent in the periods 1984-1996 and 1996-2001 ( -0.13 and $-0.26 \mathrm{~m} /$ year). Meanwhile, the descent rates were significant in 1984-1996, 1996-2001, 2009-2010 and 2010-2011 (0.6-1.8 m/year), with the ascent rate of 2011-2013 being the only relevant one $(0.9 \mathrm{~m}$ /year).

- Area 10 (collapses; Figure 9) had a high rate of ground descent in 2009-2010 (-0.59 m/year). It presented significant descent rates in 2009-2010, 2010-2011 and 2011-2013 (1-4 m/year), with a significant ascent rate in 2009-2010 (3.76 m/year).

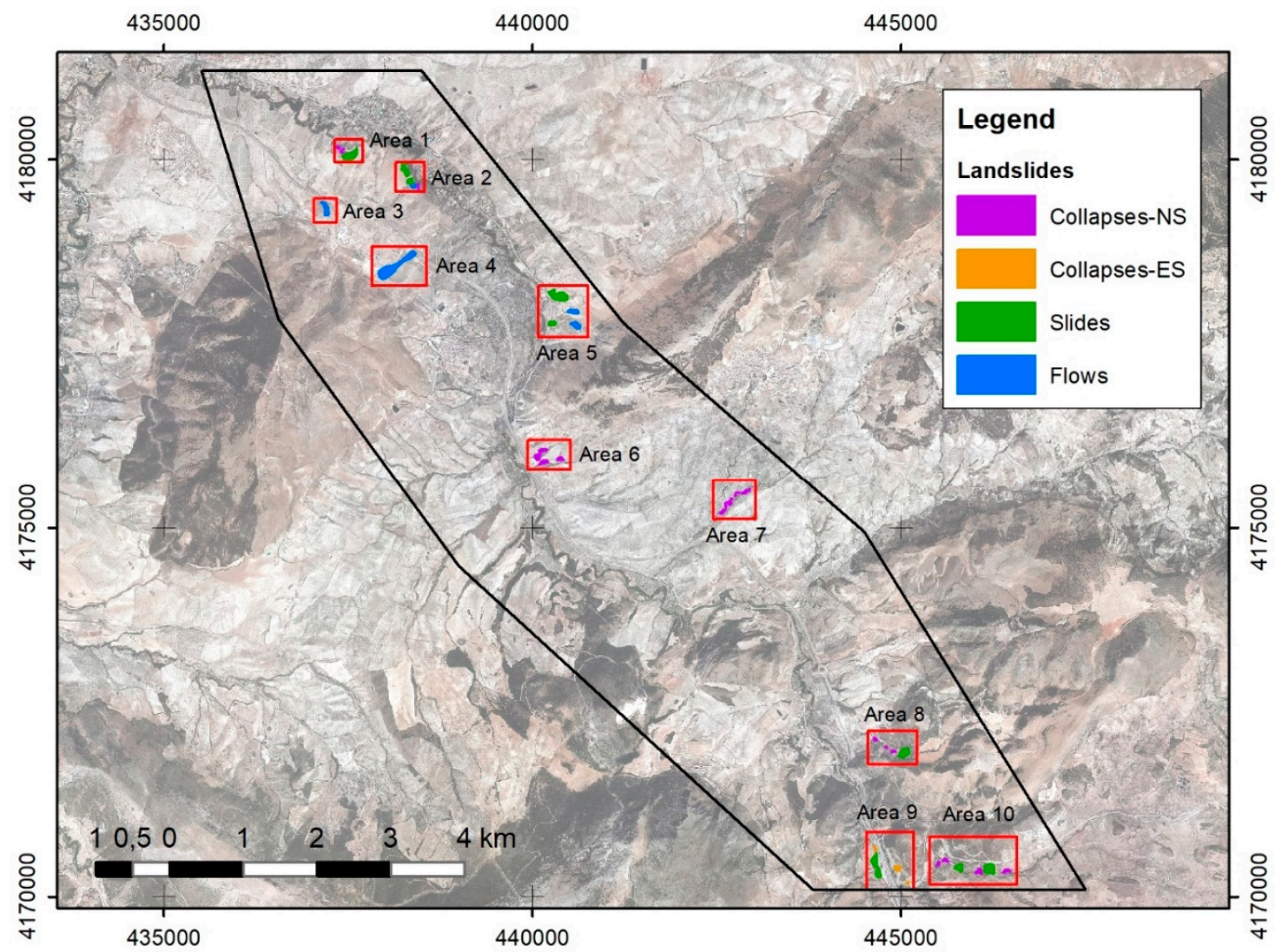

Figure 6. Monitoring areas. Coordinates are in ETRS89-UTM30. 
Table 6. Analysis of the monitoring areas.

\begin{tabular}{|c|c|c|c|c|c|c|c|c|}
\hline Area & Typology & H. Aver. & H. Min. & H. Max. & H. Range & Slope & Ori. & Lithol. \\
\hline 1 & Col-NS & 485 & 464 & 509 & 44.65 & 35.90 & 347 & 2 \\
\hline 2 & Slides & 498 & 482 & 513 & 31.11 & 26.66 & 21 & 2 \\
\hline 3 & Flows & 580 & 557 & 605 & 47.51 & 13.16 & 346 & 2 \\
\hline 4 & Flows & 629 & 577 & 671 & 94.04 & 11.06 & 38 & 8 \\
\hline 5 & Slides & 569 & 543 & 598 & 55.20 & 23.57 & 282 & 2 \\
\hline 6 & Col-NS & 576 & 557 & 596 & 39.80 & 30.62 & 192 & 6 \\
\hline 7 & Col-NS & 643 & 629 & 657 & 27.66 & 36.90 & 153 & 6 \\
\hline 8 & Col-NS & 773 & 757 & 792 & 34.78 & 30.07 & 279 & 2 \\
\hline 9 & Col-ES & 662 & 641 & 688 & 47.87 & 34.02 & 250 & 3 \\
\hline 10 & Col-NS & 727 & 703 & 752 & 48.65 & 36.39 & 200 & 3 \\
\hline All & Col-NS & 620 & 599 & 642 & 42.61 & 31.01 & 185 & 2 \\
\hline \multicolumn{9}{|c|}{ Rates of height differences (DoD) } \\
\hline Area & 1984-1996 & 1996-2001 & 2001-2005 & 2005-2009 & 2009-2010 & 2010-2011 & 2011-2013 & 2013-2016 \\
\hline 1 & 0.00 & -0.01 & 0.01 & 0.01 & -0.30 & -0.16 & -0.03 & 0.01 \\
\hline 2 & 0.00 & -0.01 & 0.01 & 0.01 & -0.21 & 0.03 & -0.05 & 0.00 \\
\hline 3 & 0.00 & 0.00 & 0.00 & 0.01 & -0.11 & -0.04 & -0.07 & 0.01 \\
\hline 4 & 0.00 & -0.01 & 0.00 & 0.00 & -0.03 & 0.00 & -0.05 & 0.01 \\
\hline 5 & 0.00 & -0.01 & -0.01 & 0.02 & -0.17 & -0.04 & -0.03 & 0.00 \\
\hline 6 & -0.01 & -0.02 & 0.01 & 0.02 & -0.14 & -0.05 & -0.03 & -0.01 \\
\hline 7 & 0.00 & 0.00 & -0.02 & 0.03 & -0.42 & -0.03 & -0.02 & 0.01 \\
\hline 8 & 0.00 & 0.00 & 0.00 & 0.01 & -0.45 & 0.04 & -0.03 & -0.02 \\
\hline 9 & -0.13 & -0.26 & 0.01 & 0.02 & -0.10 & -0.09 & -0.01 & 0.00 \\
\hline 10 & 0.02 & -0.09 & 0.02 & 0.01 & -0.59 & -0.16 & -0.02 & -0.02 \\
\hline All & -0.01 & -0.05 & 0.00 & 0.01 & -0.24 & -0.05 & -0.03 & 0.00 \\
\hline \multicolumn{9}{|c|}{ Rates of height differences in sector with descents } \\
\hline Area & 1984-1996 & 1996-2001 & 2001-2005 & 2005-2009 & $2009-2010$ & 2010-2011 & 2011-2013 & 2013-2016 \\
\hline 1 & -0.14 & -0.53 & -0.43 & -0.41 & -2.05 & -3.99 & -1.36 & -0.66 \\
\hline 2 & -0.12 & -0.40 & -0.43 & -0.53 & -1.61 & -1.44 & -1.01 & -0.73 \\
\hline 3 & -0.10 & -0.37 & -0.37 & -0.28 & -3.11 & -1.10 & -0.58 & -0.57 \\
\hline 4 & -0.16 & -0.28 & -0.33 & -0.37 & -1.28 & -1.34 & -0.69 & -0.51 \\
\hline 5 & -0.11 & -0.27 & -0.36 & -0.39 & -1.68 & -1.38 & -0.65 & -0.50 \\
\hline 6 & -0.42 & -0.27 & -0.40 & -0.38 & -1.31 & -2.93 & -1.22 & -0.71 \\
\hline 7 & -0.11 & -0.31 & -0.45 & -0.55 & -2.57 & -1.59 & -0.81 & -0.81 \\
\hline 8 & -0.20 & -0.30 & -0.42 & -0.39 & -2.01 & -1.40 & -0.90 & -0.60 \\
\hline 9 & -0.57 & -0.82 & -0.56 & -0.39 & -1.76 & -1.38 & -0.82 & -0.60 \\
\hline 10 & -0.23 & -0.50 & -0.88 & -0.63 & -4.10 & -1.75 & -0.85 & -0.78 \\
\hline All & -0.32 & -0.52 & -0.50 & -0.46 & -2.65 & -2.60 & -0.99 & -0.66 \\
\hline \multicolumn{9}{|c|}{ Rates of height differences in sector with ascents } \\
\hline Area & 1984-1996 & 1996-2001 & 2001-2005 & 2005-2009 & $2009-2010$ & $2010-2011$ & 2011-2013 & 2013-2016 \\
\hline 1 & 0.17 & 0.32 & 0.45 & 0.44 & 1.69 & 2.47 & 1.80 & 0.60 \\
\hline 2 & 0.12 & 0.33 & 0.48 & 0.43 & 1.88 & 1.61 & 0.78 & 0.59 \\
\hline 3 & 0.27 & 0.28 & 0.36 & 0.47 & 1.41 & 1.10 & 0.00 & 0.46 \\
\hline 4 & 0.12 & 0.46 & 0.36 & 0.61 & 1.58 & 1.52 & 0.71 & 0.57 \\
\hline 5 & 0.10 & 0.27 & 0.36 & 0.40 & 1.53 & 1.27 & 0.65 & 0.49 \\
\hline 6 & 0.14 & 0.34 & 0.36 & 0.34 & 1.51 & 2.14 & 1.48 & 0.56 \\
\hline 7 & 0.13 & 0.33 & 0.37 & 0.68 & 2.15 & 1.48 & 1.16 & 0.54 \\
\hline 8 & 0.13 & 0.29 & 0.40 & 0.54 & 1.41 & 1.52 & 0.88 & 0.56 \\
\hline 9 & 0.22 & 0.47 & 0.45 & 0.47 & 1.45 & 1.35 & 0.86 & 0.51 \\
\hline 10 & 0.49 & 0.38 & 0.68 & 0.82 & 3.76 & 2.42 & 1.25 & 0.66 \\
\hline All & 0.26 & 0.36 & 0.50 & 0.61 & 2.35 & 1.98 & 1.29 & 0.58 \\
\hline
\end{tabular}

Height average, minimum, maximum and range are in m. Lithology: 2: marls (Betic Ranges; 3: lutites (Triassic); 6: marls (Miocene); 8: glacis (Quaternary). Rates are in $\mathrm{m}$ /year. 


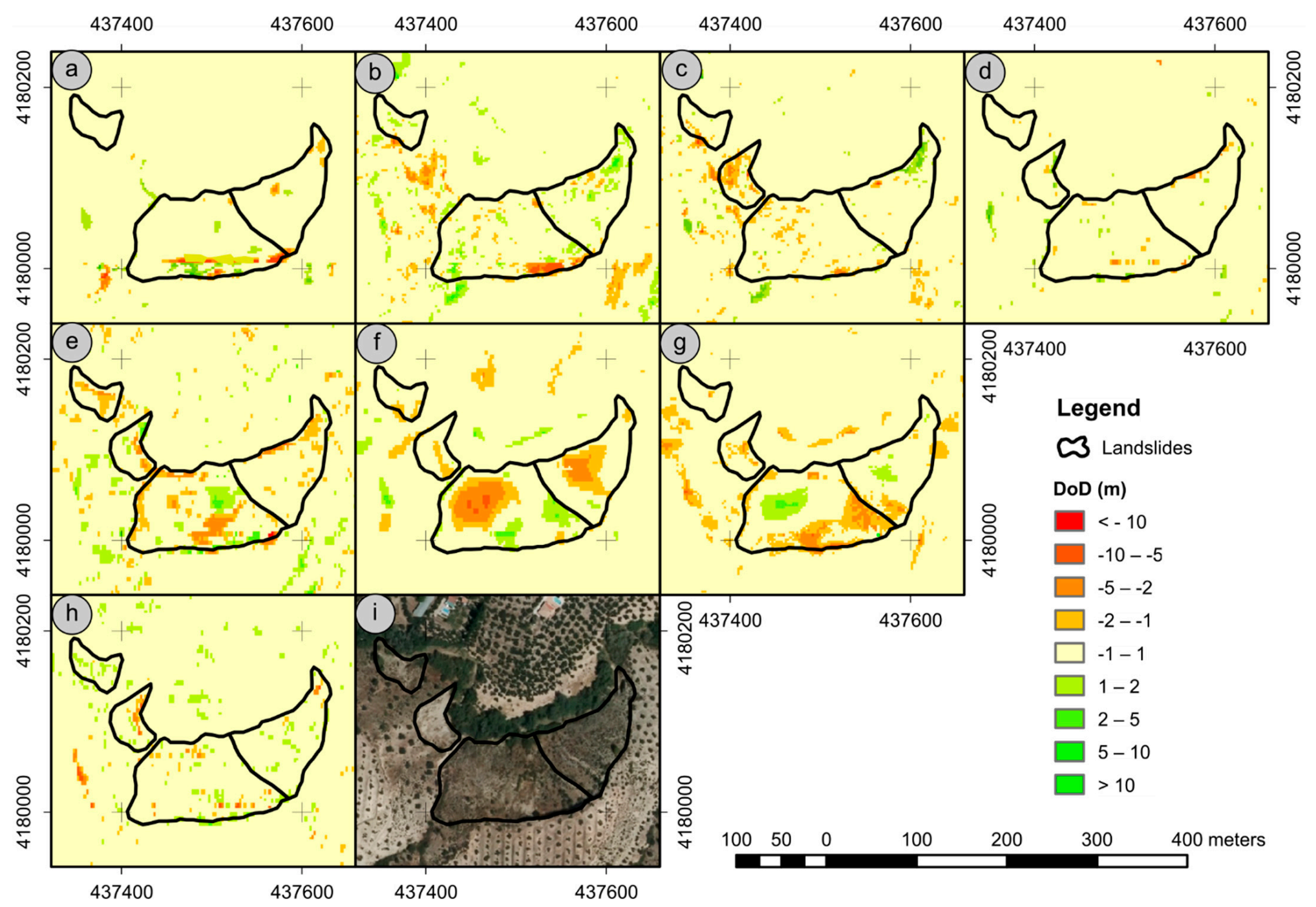

Figure 7. DoDs of the area 1: (a) 1984-1996; (b) 1996-2001; (c) 2001-2005; (d) 2005-2009; (e) 2009-2010; (f) 2010-2011; (g) 2011-2013; (h) 2013-2016; (i) orthoimage (2016). Coordinates are in ETRS89-UTM30. Location of area 1 is shown in Figure 6. 

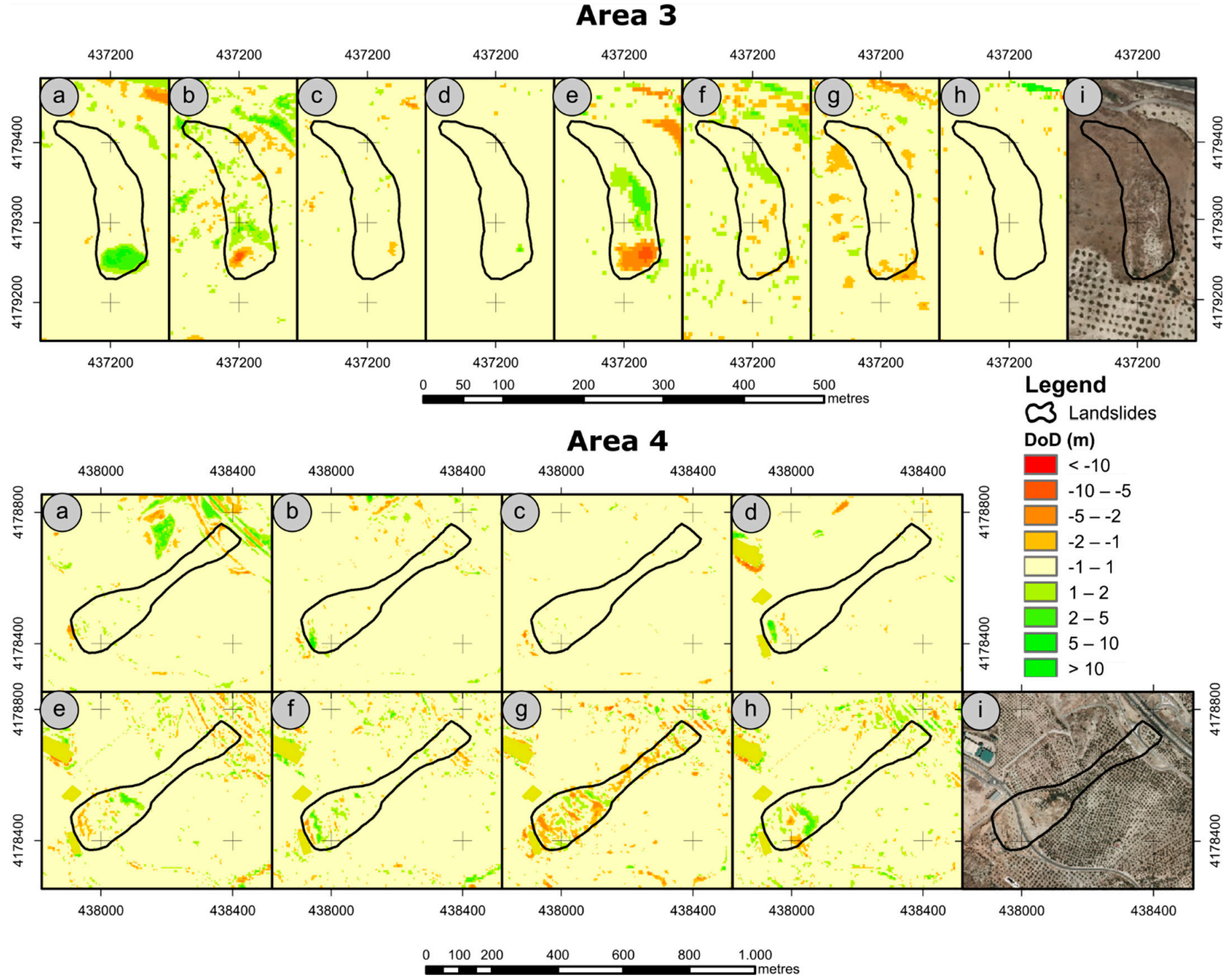

Figure 8. DoDs of areas 3 and 4: (a) 1984-1996; (b) 1996-2001; (c) 2001-2005; (d) 2005-2009; (e) 2009-2010; (f) 2010-2011; (g) 2011-2013; (h) 2013-2016; (i) orthoimages (2016). Coordinates are in ETRS89-UTM30. Locations of areas 3 and 4 are shown in Figure 6. 


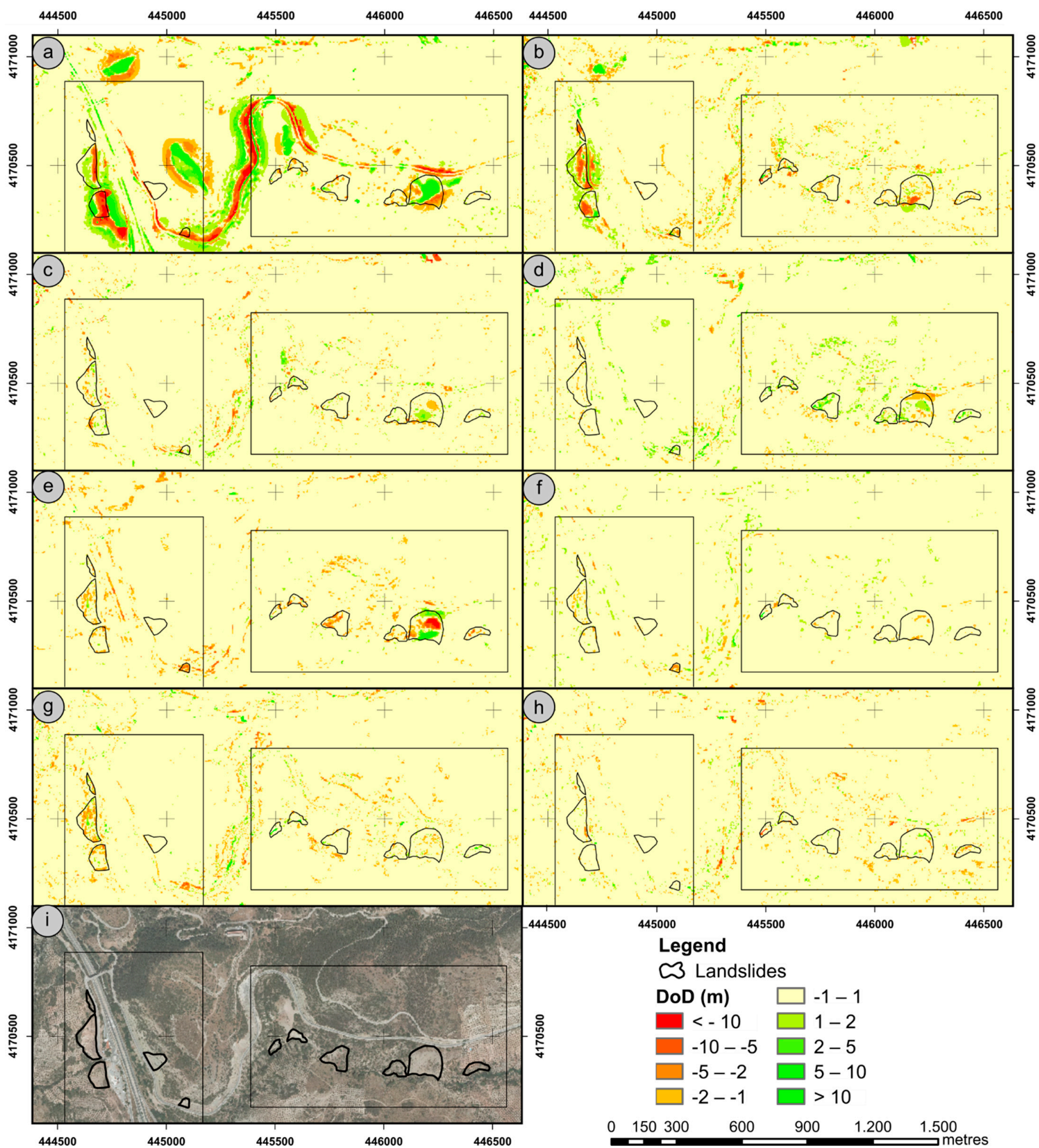

Figure 9. DoDs of areas 9 and 10: (a) 1984-1996; (b) 1996-2001; (c) 2001-2005; (d) 2005-2009; (e) 2009-2010; (f) 2010-2011; (g) 2011-2013; (h) 2013-2016; (i) orthoimage (2016). Coordinates are in ETRS89-UTM30. Locations of area 9 and 10 are shown in Figure 6.

Overall, the areas showed an outstanding value of general descent in 2009-2010 (-0.24 m/year), with lower values in the periods 1996-2001, 2010-2011 and 2011-2013 (between -0.03 and $-0.05 \mathrm{~m} /$ year), and practically null values in the remaining periods (1984-1996, 2001-2005, 2005-2009 and 2013-2016). 


\section{Discussion}

\subsection{Accuracy and Uncertainties}

As previously explained, the uncertainty of the DSMs was estimated from the RMS (vertical) errors calculated at the GCPs used in the photogrammetric orientation. In previous studies $[11,16,45]$, this uncertainty has been considered as two or three times the residual $\mathrm{RMS}_{Z}$ errors at these points. Moreover, as the different photogrammetric flights had been oriented from second-order GCPs extracted from the reference flight (2010), there was an error propagation. Finally, the uncertainties of DoDs were estimated from the uncertainties of the pairs of flights compared. Thus, the obtained $\mathrm{RMS}_{Z}$ errors ranged from 0.09 to $0.22 \mathrm{~m}$ with the DSM uncertainties between 0.25 and $0.55 \mathrm{~m}$, and the DoD uncertainties between 0.35 and $0.70 \mathrm{~m}$ (Table 3). Thus, in a conservative manner, a minimum level of detection (minLoD) $[32,49,53]$ was established at $\pm 1 \mathrm{~m}$.

These values are comparable to those obtained in previous studies of the research group in which similar methodologies were applied in order to analyze the evolution of an active landslide [16] and a gully system [45], although with some differences depending on the available data. In both studies, photographs of the same dates and properties (national and regional flights) were used. In addition, they are of same order of magnitude as other studies by different authors [11,14].

\subsection{Height Differences}

The calculation of the height differences of the ground surface between successive dates allowed the observation of some general processes. First, there were some sectors where extensive changes occurred related to the growth or decrease in vegetation due to natural, agricultural or forestry activities. Thus, pine and holm oak forests could grow or be cleared, and scrubs or shrubs could suffer changes, although in the last case, their effects were less significant. In the same way, olive groves-the dominant crop in the study areaunderwent more or less significant modifications throughout the study period, although these are difficult to detect as they are single isolated trees separated by several meters from each other. In any case, most of these changes were discarded by means of the application of an NDVI filter to remove extensive areas and, in some cases, with the help of mode or mean filters to remove the effect of isolated trees (Figure 4).

In addition to vegetation, urban areas (populations, industrial, isolated buildings, roads, constructions, etc.) and water bodies (river and wetlands) were removed by applying masks from vector layers (Figure 4), since in these areas changes not related to the ground surface could occur. However, some changes in the ground surface in the surroundings of urban or construction areas, such as human-made excavations, explorations or infills, had remained. Among them, the earthworks related to the construction of the A-44 highway in the mid-1990s could be observed as well as other minor works of cutting, grading and fillings related to civil engineering and agricultural activities. These areas could have been removed by means of the application of corridors (buffers) along these constructions, but in this case, we preferred to keep them because some landslides originated in the cut slopes after the construction works. The effect of roads and construction was considered and then discarded for the landslide inventory by means of photointerpretation. Thus, the highway roadworks appeared clearly in the first period of 1984-1996 and to a lesser extent in the second period of 1996-2001, while other minor works could be observed in these and other intervals.

Once the effects of previous elements (vegetation, urban areas, water bodies and earthworks) had been removed, the height differences observed in the maps (Figures 7-9) should correspond to changes in the ground surface, although some isolated vegetated and urban areas could remain, as well as some artifacts and misalignments. These last elements were also discarded by photointerpretation. Thus, natural changes in the ground surface, such as landslides, erosion processes and subsidence, could be detected. The interpretation of these changes as landslides was undertaken from orthoimages but also from DoD analysis. For example, the observation of adjacent depletion and deposition 
areas from DoDs could be related to landslides (Figures 7-9). When discarding general subsidence processes in the area, gully erosion or small karstic subsidence processes in relation to gypsum bodies could occur. Erosion processes were well identified [45], and thus the depletion and accumulation areas in the bottom and lateral walls of the gullies were not considered as landslides, although some small landslides (mainly collapses) in the lateral walls were inventoried. Small karstic subsidence cavities were also well identified in the orthoimages, and thus they were discarded as landslides.

\subsection{Landslide Inventory and Factor Analysis}

As previously mentioned, three basic typologies were distinguished in the area: fallscollapses, slides and flows. Practically no falls in the strict sense were identified in the study period (1984-2016), but there were many examples of collapses that occurred in the lateral walls of riverbeds and gullies, as well as in engineering slopes, which were considered in this study as separate classes. Meanwhile, the slides were mostly earth slides, but they were always shallow movements of a few meters in depth. Flows were mostly earth flows, although in some cases, they may have been in transition to mud flows; nevertheless, they were also movements with a depth of a few meters and a length of hectometric magnitude. Deep slides or large flows that appear in this area [35] and similar ones [57-59] have not presented any evidence of activity in recent years. The same occurs with debris flows that also appear in the surrounding ranges but with no activity in recent years in the study area.

The percentage of mobilized area, near to $2 \%$, was higher than other values found for recent landslides (active or suspended, according to [56]) in previous studies in a wider area that includes this one (1.15\% in [35]) and in other areas with similar conditions $(0.56 \%$ in $[58,59])$. This may be due to the fact that this is a more active area with natural and artificial conditions prone to landslides. Such conditions are basically high slopes in an active geological front with marly and clayey lithologies, the excavation of a river and the construction of a highway. However, it could also be due to the elaboration of a more precise landslide inventory by means of $\mathrm{DoD}$ calculation and photointerpretation. Nevertheless, these values were lower than those calculated in landslide inventories, which also include ancient (dormant and relict) movements, in similar environments to the Betic Cordilleras [35,57-59], where percentages between 5 and 10\% have been reached. Analysis by typologies showed an area distribution (Figure 10) with a higher proportion of collapses $(63 \%)$ and slides $(25 \%)$ than flows $(12 \%)$. In the extended area, which includes ancient landslides, the percentage of rock falls reached $10 \%$, and flows increased to $55 \%$, while slides decreased to $35 \%$ [35]. If we consider the number of landslides, the proportion of collapses in natural and engineering slopes increased by nearly $85 \%$, while slides and flows decreased to 12 and 3\%, respectively, due to the small individual area of collapses (about $1000 \mathrm{~m}^{2}$ ), with respect to slides and flows (4500 and 10,800 $\mathrm{m}^{2}$, respectively) (Figure 10). 


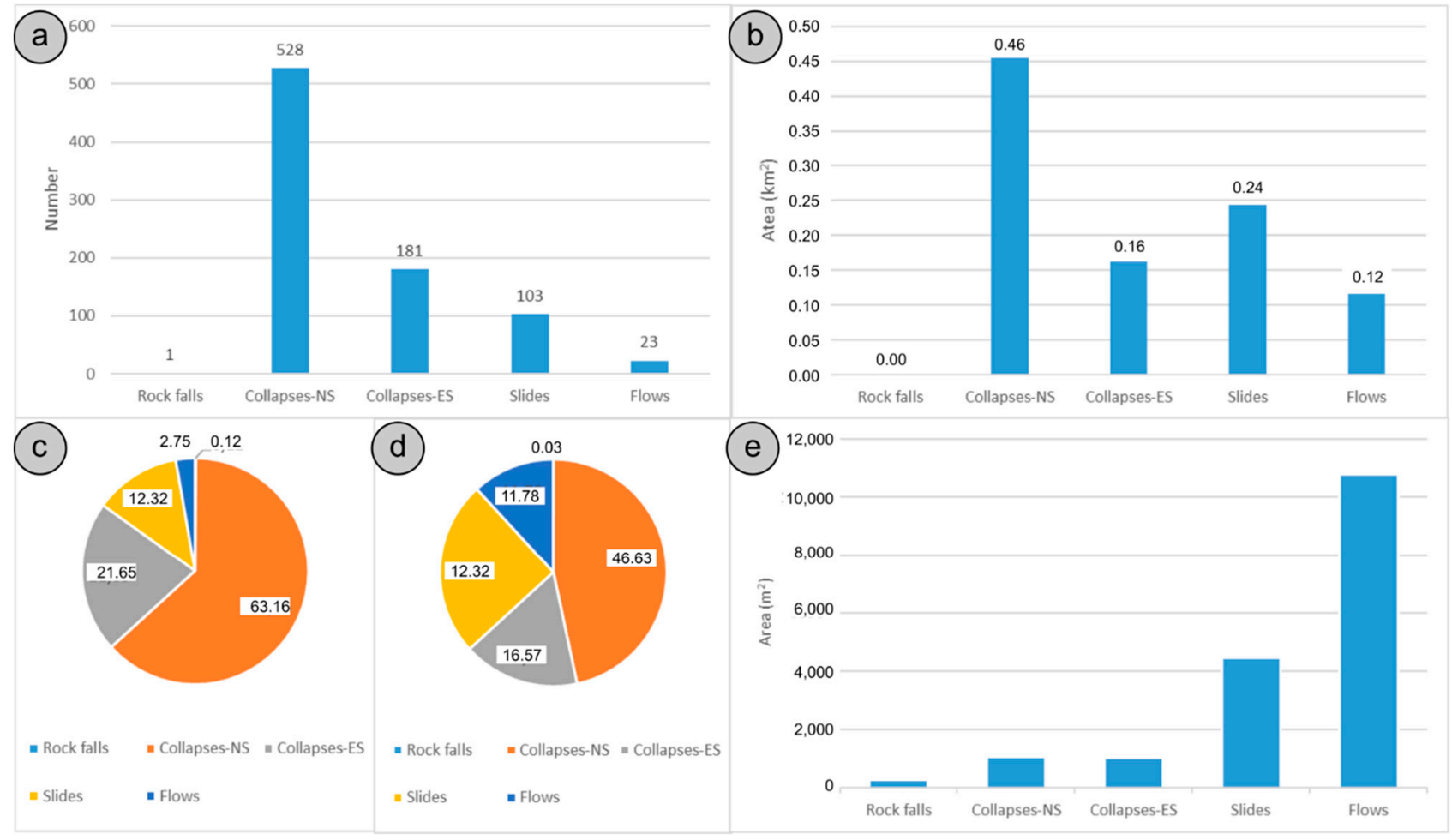

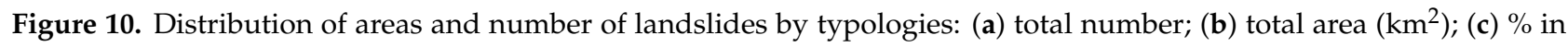
number; (d) \% in area; (e) individual areas.

Regarding the morphometry, the height interval was around $40 \mathrm{~m}$ in the rock fall that produced a high $\mathrm{H} / \mathrm{L}$ ratio of 2.23 , typical of a small movement with a high potential activity [54]. In collapses, the height interval had an average of $14-19 \mathrm{~m}$ for the natural and engineering slopes, and the $\mathrm{H} / \mathrm{D}$ ratios were in the range $0.54-0.60$, respectively. These relatively high values were also related to small movements with a moderate potential activity. Meanwhile, the height interval associated with slides and flows was about 35 $45 \mathrm{~m}$, with larger areas and lower $\mathrm{H} / \mathrm{L}$ ratios (0.44-0.19), suggesting a lower level of potential activity.

The analysis of determinant factors and the conditions associated with landslides is usually an initial step in susceptibility modelling $[59,60]$. These conditions are different for each typology since they correspond to different mechanisms $[38,39,59]$. Thus, the rock fall appeared in a steep slope (average of $60^{\circ}$ ) of the higher part of the area, where limestones of the Betic ranges outcropped. Collapses were concentrated in a narrow range of height between 600 and $630 \mathrm{~m}$, with average slopes of around $30^{\circ}$, excavated mostly in Miocene and Cretaceous marls and also in Pliocene-Quaternary deposits (conglomerates and sands). Slides were associated with slopes of between 20 and $30^{\circ}$ formed mostly in Cretaceous and Neogene marls and Triassic lutites. Flows originated in slopes of between 10 and $25^{\circ}$, oriented mainly to $\mathrm{N}$ and $\mathrm{NE}$, and formed mostly in Cretaceous-Neogene marls and clays. These conditions are very similar to those in which the different landslides occur in other areas of the Betic Cordilleras [35,57-59], although the slopes are somewhat steeper in this area.

Finally, the average height differences (DoDs) corresponded to average descents ranging from very low values $(-0.13 \mathrm{~m})$ in flows to values near $-1 \mathrm{~m}$ in slides, -1.2 to $-1.6 \mathrm{~m}$ in collapses and $-2.2 \mathrm{~m}$ in rock falls. This seems consistent with the kinematics and evolution of landslides observed in other studies [19,27,31]. Usually, greater descents of the ground surface are observed in the landslide head or scarp, although more concentrated in space, while lower ascents are observed at the foot area, although these can be more widely distributed [61]. This causes a higher proportion of the ascents to be below the uncertainty threshold with respect to the descents, which leads to an average surface descent in the 
balance. Moreover, a proportion of the deposit masses accumulated at the foot of the slope can be eroded and evacuated by the drainage network [16,21]. This effect also depends on the landslide typology. Thus, the movements with steep scarps, such as collapses, show significant descents of the ground surface in the landslide head and much lower ascents (in many cases under the uncertainty threshold) in the foot or accumulation zone. Meanwhile, flows undergo small descents in the head and even smaller ascents in the foot, since the horizontal displacements predominate over the vertical ones.

\subsection{Multitemporal Inventory Analysis}

The analysis of multitemporal inventories is suitable for landslide hazard modelling [3,62]. In this case, it led us to observe changes in activity (Figure 11), 2009-2010 and 2011-2013 being the periods with the highest activity, both in affected area ( 0.35 and $0.33 \mathrm{~km}^{2}$, respectively) and in landslide number (196 and 149). After these, the periods 2010-2011 and 1996-2001 presented areas of around $20 \mathrm{~km}^{2}$ and 135 landslides. The periods 2013-2016 and 1984-1996 had the lowest activity, with about $0.15 \mathrm{~km}^{2}$ and 80 landslides, and especially 2001-2005 and 2005-2009 when the area decreased to $0.07-0.02 \mathrm{~km}^{2}$ and the number to 32-33 landslides. The proportion of areas of the typologies with larger individual areas, such as slides and flows, was greater in the more active periods (33 and $16 \%$, respectively, in 2009-2010) than in the less active ones (7 and 0\% in 2005-2009), unlike the collapses. However, if we consider the number of landslides, the proportion was more uniform between the different periods, about $12 \%$ for slides, $3 \%$ for flows and more than $80 \%$ for collapses.
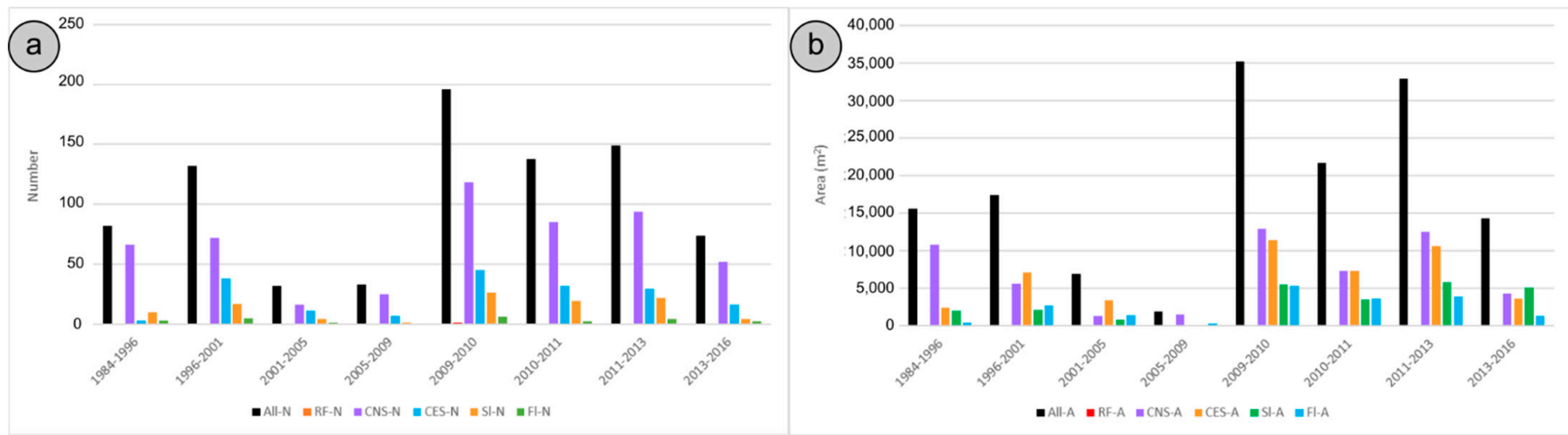

Figure 11. Activity of landslides in the different periods considered: (a) number of landslides (N); (b) total areas (A). RF: rock falls; CNS and CES: collapses in natural and engineering slopes; Sl: slides; Fl: flows.

Regarding individual areas and morphometric parameters, collapses maintained relatively uniform areas and height intervals around the aforementioned average values (1000 $\mathrm{m}^{2}$ and 15-20 m, respectively). Slides showed some differences in the areas (2000$\left.8000 \mathrm{~m}^{2}\right)$ and height intervals $(25-60 \mathrm{~m}$ ) but without a clear pattern between more or less active periods. Meanwhile, flows showed a certain tendency between less active periods (areas lower than $8000 \mathrm{~m}^{2}$ and height intervals lower than $35 \mathrm{~m}$ ) and the more active periods (larger than 10,000 $\mathrm{m}^{2}$ and greater than $40 \mathrm{~m}$, respectively). However, the largest dimensions were found in $2013-2016\left(25,000 \mathrm{~m}^{2}\right.$ and $\left.66 \mathrm{~m}\right)$. This is due to the fact that some flows of larger dimensions, originated or reactivated in the previous periods (2009-2013), were still active in the first months of this period before their stabilization [21]. Meanwhile, the $\mathrm{H} / \mathrm{L}$ ratio was also uniform throughout the different periods for all types of landslides.

Most conditions in which the different typologies of landslides occurred, such as height, slope and geology, did not change significantly over the different periods, since these conditions are more related to the typology than the activity. Nevertheless, when we analyze all the movements, we can find some differences related to the different proportions of landslide typologies throughout the different periods. Thus, less active periods with a higher proportion of collapses presented greater slopes $\left(31-33^{\circ}\right)$ than the most active (about 
$28-29^{\circ}$ ). In the same way, the predominant lithology in periods with a high proportion of collapses in engineering slopes (1996-2001 and 2001-2005) were the Quaternary deposits, while in the remaining periods, the Miocene marls predominated.

Finally, the average height differences between DSMs were always negative (ground descent), but they showed greater absolute values in the periods of high activity in landslide number and area. Thus, in the less active periods (1984-1996, 2001-2005 and 2013-2016), the height differences were between -0.5 and $-0.7 \mathrm{~m}$, while in the more active periods (1996-2001, 2009-2010, 2010-2011 and 2011-2013), the height differences were about -1 m. By typologies, collapses remained relatively uniform at values of between -1 and $-2 \mathrm{~m}$. However, slides presented greater descents in the more active periods (more than 1.0 in absolute value for 1996-2001 and 2009-2010) than in the less active ones (under $0.5 \mathrm{~m}$ for 1984-1996, 2001-2005, 2005-2009 and 2013-2016), which agrees with observations of individual slides studied previously [16]. Flows presented very low and even null average values, but they reached significant average descents (between -0.2 and $-0.4 \mathrm{~m}$ ) in those periods of more activity (1996-2001, 2009-2010 and 2011-2013).

In summary, in the periods of higher activity, the movements were more abundant; the area affected was also larger; some typologies, such as flows, had greater dimensions; and, in particular, they presented a greater average descent of the ground surface. Meanwhile, in the periods with lower activity, fewer movements were originated, the affected areas were smaller and the average descents of the ground surface were lower and even null. The exception is the period 2013-2016, which was of general low activity, in which some large flows and slides originating in the previous periods continued their activity [21].

\subsection{Analysis of the Monitoring Areas}

This analysis allowed the monitoring of a set of common landslide areas throughout the whole period, which can be used in further landslide hazard modelling [62]. Regarding the morphometry, in areas 1, 6, 7, 8,9 and 10 (Figures 7 and 9), where collapses predominate, the dimensions are around $2800 \mathrm{~m}^{2}$ (area) and 30-50 m (height interval), somewhat greater than the average of collapses in the inventories, since in these areas there are also slides and flows. In areas 2 and 5, where slides predominate, the dimensions are around $9800 \mathrm{~m}^{2}$ and $30-55 \mathrm{~m}$, respectively, which are similar to those found in the inventories. Finally, in areas 3 and 4 (Figure 8), where only one flow was considered, the dimensions are about $16,000 \mathrm{~m}^{2}$ and $50-100 \mathrm{~m}$.

Observing the height differences and especially their rates (Figure 12), greater rates of general descent of the ground surface were observed in the period 2009-2010 $(-0.24 \mathrm{~m} /$ year). Lower rates were found in the periods 1996-2001, 2010-2011 and 2011-2013 (about -0.03 and $-0.05 \mathrm{~m} /$ year), and practically null values in the remaining periods (1984-1996, 20012005, 2005-2009 and 2013-2016). Considering the sector with negative height differences within the landslides analyzed, significant descent rates were observed in the period 2009-2010 (2.65 m/year), being lower in 2011-2013 (1 m/year), 1996-2001 (0.52 m/year) and 1984-1996 (0.32 m/year). Meanwhile, significant ascent rates were only observed in 1984-1996 (0.26 m/year). These values are in accordance with those found in the inventory analysis with a period of maximum activity in 2009-2010 and other ones with a certain activity, such as 2011-2013 and 1996-2001, while the remaining periods presented low or null activity. The changes observed in some areas in the period 1984-1996, when the relatively higher descents were compensated with ascents, were mainly related to earthworks of the A44 highway. Nevertheless, these rates allowed us to catalogue the landslides as very slow (0.016-1.6 m/year) in average terms throughout the periods considered, although they could probably reach the category of slow $(1.6 \mathrm{~m} /$ year $-13 \mathrm{~m} / \mathrm{month})$ or even moderate (13 m/month-1.8 m/hour), according to the classification of WP/WLI [39,55]. 


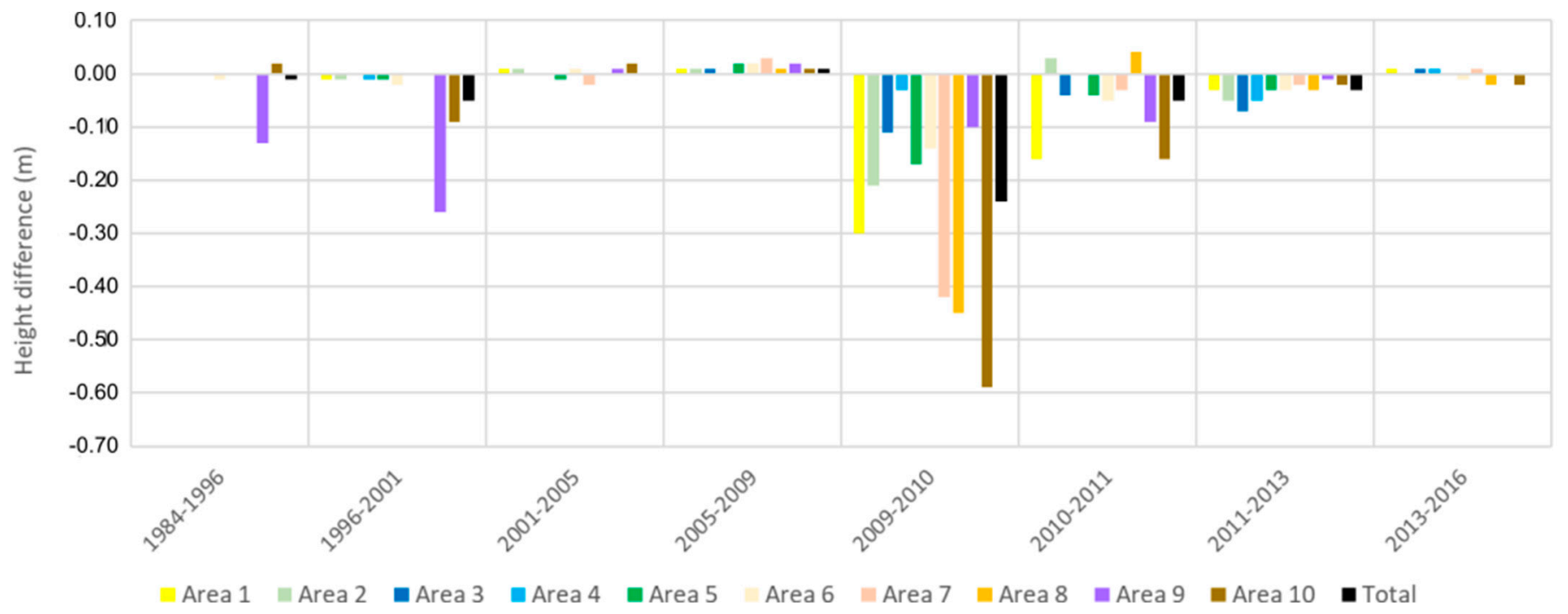

Figure 12. Evolution of height differences throughout the different periods.

In the analysis by typologies, the areas with predominance of collapses in natural slopes (Figures 7 and 9) showed general descent rates of the ground surface that reached the highest absolute values in the period 2009-2010 (between -0.15 and $-0.60 \mathrm{~m} /$ year), being lower in other periods, such as 2011-2013, 2010-2011 and 1996-2001. Considering the sectors with negative values, there were significant average descent rates in several periods, such as 2009-2010, 2010-2011 and 2011-2013, when the maximum descents were reached (greater than 1 and even up to $2 \mathrm{~m}$ /year), but also in other periods, such as 1996-2001 (usually lower than $1 \mathrm{~m}$ /year). Meanwhile, there were also sectors with significant ascent rates, such as 2009-2010 and 2011-2013. Area 9, in which collapses in engineering slopes predominate (Figure 9), showed the greatest rates of height difference in several active periods, such as 2009-2010 and 2010-2011, but also in other less active ones, such as 19841996 and 1996-2001, related to the road works of the A4 highway. In all these periods, the descent rates were greater than $1 \mathrm{~m} /$ year, and the ascent rates were lower than $1 \mathrm{~m} /$ year, in absolute terms. The average velocities for the collapses were in the boundary of very slow to slow, although this average velocity is not significant since this type of movement usually reaches rapid to very rapid velocity (more than $1.8 \mathrm{~m} /$ hour).

Areas 2 and 5, in which slides predominate, showed significant descent rates in the period 2009-2010 (about $1.6 \mathrm{~m}$ /year) and in 2009-2013 and 1996-2001 (lower than $0.5 \mathrm{~m} /$ year), with some minor ascent rates in some cases that produced a general ground descent in these periods. With these average rates, the movements were catalogued as slow, although they could reach moderate and even rapid velocity. Meanwhile, areas 3 and 4, with two significant flows studied previously by means of UAS surveys [21,36], presented sectors with significant descent and ascent rates in several years. The main changes took place in 2009-2010, when significant descent rates (1-3 m/year) and ascent rates $(0.5-1.5 \mathrm{~m}$ /year) were estimated to result in a general negative balance, although this also occurred in other active periods, such as 2010-2011 and 2011-2013. The average velocities were in the boundary of very slow to slow, but more precise measurements, in both the vertical and the horizontal component, allowed us to catalogue the flows as slow in the more active episodes. Moreover, one of these flows (area 4; Figure 8) maintained its downslope movement until the first year of the period 2013-2016 [21]. Meanwhile, the other flow (area 3; Figure 8) had a previous activity in the active period 1996-2001, with significant descents in the upper part of the slope, after an ascent in the same area in the previous period (1984-1996), which could be due to a fill of material derived from nearby quarries and works.

In summary, some periods were more active, such as the consecutive 2009-2010, 2010 2011 and 2011-2013 periods, especially the first, and previously the period 1996-2001, 
while the remaining periods, 1984-1996, 2001-2005 and 2005-2005, were much less active. Nevertheless, in some cases, such as the flows of area 4, the activity originating in active periods (2009-2013) was extended to periods of less general activity, such as 2013-2016.

\subsection{Relationships with Rainfall}

The relationships between rainfall and landslides have been well established in different environments and regions. In fact, rainfalls are the main triggering mechanism of landslides all over the world [63,64], but also in Mediterranean countries [65] and particularly in the regions near the study area [37,59].

After the analysis of landslide inventory and monitoring areas, some more active periods (1996-2001 and 2009-2013) were distinguished among other less active ones (19841996, 2001-2009 and 2013-2016). In detail, within the period 2009-2013, the year 2009-2010 was the most active, the year 2010-2011 was somewhat less active and the period 2011-2013 recorded a higher level of activity. Meanwhile, in the least active period of 2001-2009, the second part (2005-2009) was even less active than the first (2001-2005).

If we analyze the regional rainfall (Figure 13), the weekly rainfalls showed maximum values (higher than $100 \mathrm{~mm}$ ) in the autumn-winter of the years 1996-1997, 1997-1998, 1999-2000, 2009-2010, 2010-2011 and 2012-2013 [45]. In fact, the absolute maximum value of $150 \mathrm{~mm}$ was reached in November 2012. Meanwhile, the monthly rainfalls also presented maximum values (around $250 \mathrm{~mm}$ ) in the winter of 1995-1996, 1996-1997, 19971998, 2009-2010, 2010-2011 and 2012-2013, reaching a maximum absolute value of $310 \mathrm{~mm}$ in January 2010. Thus, the maximum activity of the year 2009-2010 was clearly related to the rainfalls, both weekly and monthly, of the autumn-winter of this year. Other periods of more activity were also related to rainy events: 2010-2011 to the rainfalls of winter of this year, 2011-2013 to rainfalls of the autumn-winter of 2012 and 1996-2001 to the rainfalls of the autumn-winter of 1996-1997 and 1997-1998. Meanwhile, the periods of lower activity, such as 1984-1996, 2001-2005, 2005-2009 and 2013-2016, were related to generally dry years, although some of them, such as 2001-2005 and especially 2013-2016, still showed some activity originating in the previous wet periods (2009-2013), while in 2005-2009, the least activity was observed after many dry years. In other cases, such as 1984-1996, a certain activity could be observed in a long period that was also affected by civil works of the A4 highway, especially related to the collapses in engineering slopes, as occurred in area 9 .

Some of the movements, usually those with lower dimensions, such as collapses and smaller slides, presented an episodic activity related to intense rainy events, while others, such as larger slides and flows, presented an intermittent activity with periods of lower and higher rates of movement or velocity. This is typical of landslides in Mediterranean or arid climates [65], where the rainfall regime shows an irregular distribution alternating between dry and wet years [66]. 


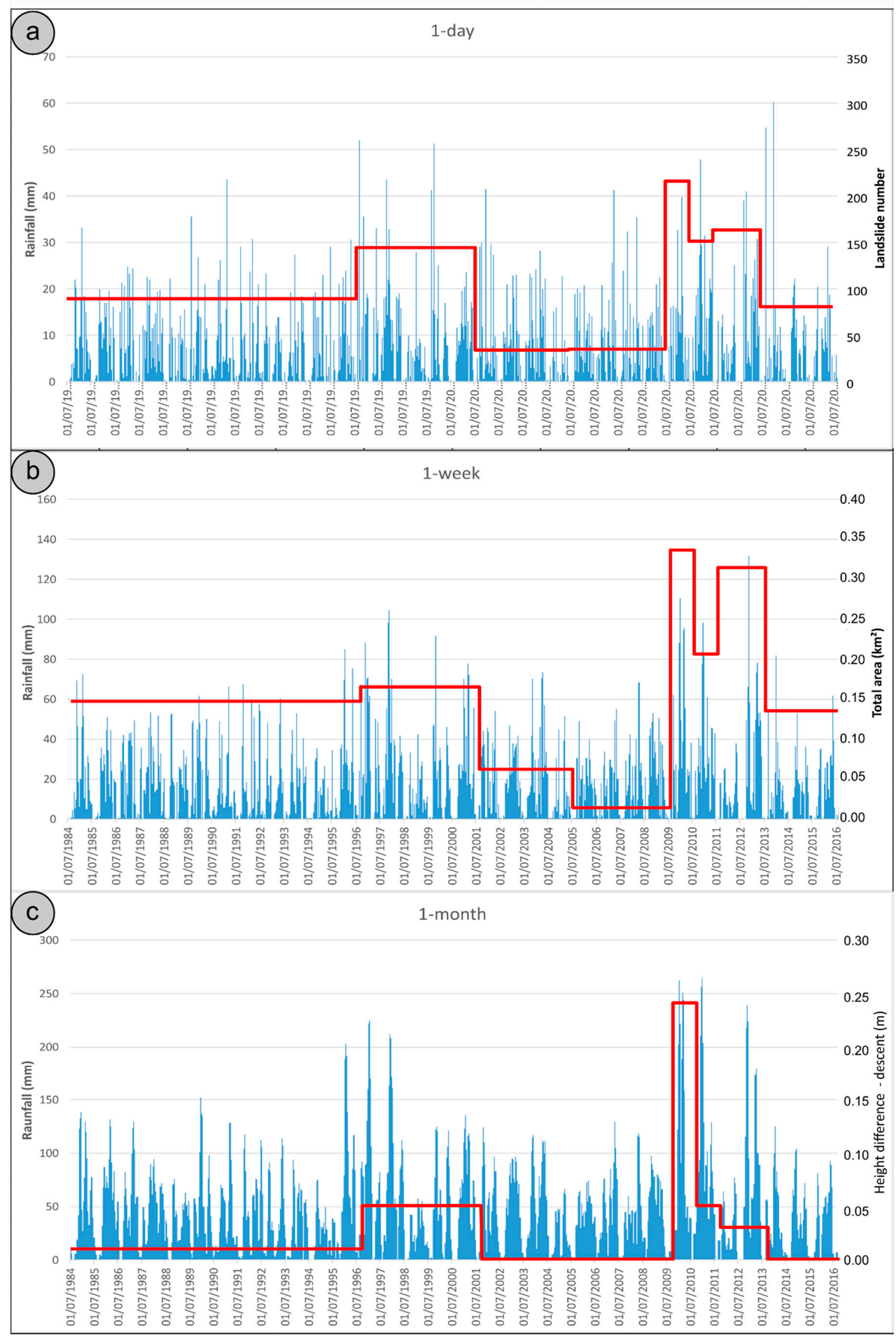

Figure 13. Relationships between landslide activity and rainfalls: (a) 1-day rainfalls and landslide number; (b) 1-week rainfalls and total area $\left(\mathrm{km}^{2}\right)$; (c) 1-month rainfalls and average height differences. 


\section{Conclusions}

The techniques of photogrammetry and LiDAR have been revealed as very useful tools for landslide identification and the characterization of their activity. LiDAR and aerial photogrammetry allow us to work with individual movements of a certain magnitude (hectometer to kilometer), but also with areas of up to several kilometers, as with the studied case (about $50 \mathrm{~km}^{2}$ ), in order to elaborate multitemporal inventories.

From historical and recent flights oriented through direct orientation procedures and iterative adjustment between models, we were able to obtain the corresponding DSMs and orthophotographs, and especially the differential models (DoDs), which showed potential unstable areas with changes in the ground surface. After a filtering process, noise was partially eliminated as well as vegetation, construction areas and water bodies. Furthermore, a threshold based on the uncertainty of DoDs of about $\pm 1 \mathrm{~m}$ was considered. Then, by means of photointerpretation in addition to DoDs analysis, landslides were identified and digitized for the different periods. GIS tools allowed the inventory and factor analysis to characterize the landslides dimensions (area, perimeter, height interval and $\mathrm{H} / \mathrm{L}$ ratio) and their properties (height, slope, orientation and lithology). Moreover, the zonal analysis of DoDs in the different periods considered led us to estimate vertical velocity as an expression of landslide activity. Nevertheless, this analysis was complemented with other analyses focused on a common set of landslide monitoring areas, in which the activity was monitored in a more specific way.

The inventory first shows a more extensive and detailed inventory than that obtained only with photointerpretation for recent movements in other areas with similar characteristics to the Betic Cordilleras, although it is less extensive than those inventories that include ancient movements, as can be also observed in other areas of the region. Thus, the proportion of small landslides, such as collapses and slides, in this area is higher than large slides and flows, in terms of affected area but especially in landslide number. However, the conditions in which landslides occur are practically the same, that is, great slopes $\left(30^{\circ}\right.$ or more) in different lithologies for collapses and rock falls, middle slopes $\left(20-30^{\circ}\right)$ in marls and lutites for slides, and lower slopes $\left(10-20^{\circ}\right)$ in marls and clays for flows. The multitemporal analysis showed periods with greater activity, mainly 2009-2010 but also 1996-2001, 2010-2011 and 2011-2013, where the landslides were usually more frequent and larger, regarding the remaining periods.

The average of height differences between DSMs (DoDs) ranged from $-0.13 \mathrm{~m}$ in flows to values of between -1 and $-1.6 \mathrm{~m}$ in slides and collapses and $-2.2 \mathrm{~m}$ in rock falls. However, the activity is highly variable over time, with periods of much greater activity of most landslide typologies, such as 1996-2001, 2009-2010, 2010-2011 and 2011-2013, and others with lower activity, such as 1984-1996, 2001-2005, 2005-2009 and 2013-2016. These results are corroborated by the analysis of monitoring areas, where the period 2009-2010 stands out as very active, which can be correlated to the more intense episode of rainfalls that occurred in the autumn-winter of this year. After that, the periods 1996-2001, 20102011 and 2011-2013 presented moderate activity, also related to rainy events in some of these years. Meanwhile, the scarce activity observed in the remaining periods is related to dry years, typical of the rainfall regime of Mediterranean areas.

Both the multitemporal inventory elaborated in this study and the consequent factor and temporal analyses constitute the starting point of susceptibility and hazard modelling. Currently, a great variety and quantity of landslide hazard approaches are available [60,62], but they must be based on accurate multitemporal inventories [2,3].

Future research will focus on adding more flights, both those corresponding to official plans, as they become available in public SDI, and those carried out ad hoc, such as UAS flights, in order to perform a more complete monitoring of the activity of the area. LiDAR data should be also incorporated into the analyses since they allow us to obtain more accurate DSMs and DTMs. Meanwhile, filtering techniques must be improved to perform better discrimination between areas with changes in the DSMs and areas where landslides have 
actually occurred. Machine and deep learning techniques should also be implemented for the automatic detection of landslides and other processes, such as erosion and subsidence.

Author Contributions: Conceptualization: T.F., J.L.P.-G. and J.D.; field work: T.F., J.L.P.-G., J.M.G.-L. and F.M.; methodology: T.F., J.L.P.-G., J.M.G.-L. and J.C.; processing of photogrammetric data: J.L.P.G., J.M.G.-L. and J.C.; GIS analysis: T.F. and F.M.; data interpretation: T.F. and J.C.; supervision: J.D.; writing, editing and preparation of figures: T.F. and J.C.; funding acquisition: T.F. and J.D. All authors have read and agreed to the published version of the manuscript.

Funding: This work was financed by the following projects: SPS-LIDAR (National Research Agency of Spain; ref. RTI2018-099638-B-I00); ISTEGEO (Excellence project of the Regional Government of Andalusia, ref. RNM-06862,); “Development of a methodology for the landslide hazard mapping: Application to the province of Jaén" (Center for Advanced Studies in Earth Sciences, Energy and Environment of the University of Jaén); the Convene "Risks associated to the Road Network of the Jaén Province" of the Deputy of Jaén; and the "Photogrammetric and Topometric Systems" Group of the Andalusian R \& D \& I Plan (TEP213, PAIDI).

Institutional Review Board Statement: Not applicable.

Informed Consent Statement: Not applicable.

Data Availability Statement: Not applicable.

Acknowledgments: We acknowledge our colleagues Mario Sánchez and Julio Calero in the geological discussion and interpretation and Joaquín Tovar for climatic data, as well as the work of Margarita Castillo in helping with field and lab work. We also thank Nick Snow for his valuable review of the English manuscript.

Conflicts of Interest: The authors declare no conflict of interest.

\section{References}

1. Varnes, D.J. Landslide Hazard Zonation: A Review of Principles and Practice, Natural Hazards; UNESCO: Paris, France, 1984.

2. Brabb, E.E. The world landslide problem. Episodes 1991, 14, 52-61. [CrossRef]

3. Guzzetti, F.; Mondini, A.C.; Cardinali, M.; Fiorucci, F.; Santangelo, M.; Chang, K.T. landslide inventory maps: New tools for an old problem. Earth-Sci. Rev. 2012, 112, 42-66. [CrossRef]

4. Brunsden, D. Mass movements; the research frontier and beyond: A geomorphological approach. Geomorphology 1993, 7, 85-128. [CrossRef]

5. Chacón, J.; Irigaray, C.; Fernández, T.; El Hamdouni, R. Engineering geology maps: Landslides and geographical information systems (GIS). Bull. Eng. Geol. Environ. 2006, 65, 341-411. [CrossRef]

6. Metternicht, G.; Hurni, L.; Gogu, R. Remote sensing of landslides: An analysis of the potential contribution to geo-spatial systems for hazard assessment in mountainous environments. Remote Sens. Environ. 2005, 98, 284-303. [CrossRef]

7. Scaioni, M.; Longoni, L.; Melillo, V.; Papini, M. Remote sensing for landslide investigations: An overview of recent achievements and perspectives. Remote Sens. 2014, 6, 9600-9652. [CrossRef]

8. Zhao, C.; Lu, Z. Remote sensing of landslides-A review. Remote Sens. 2018, 10, 279. [CrossRef]

9. Walstra, J.; Chandler, J.H.; Dixon, N.; Dijkstra, T.A. Time for change-Quantifying landslide evolution using historical aerial photographs and modern photogrammetric methods. In The International Archives of the Photogrammetry, Remote Sensing and Spatial Information Sciences, Proceedings of the 20th ISPRS Congress, Istanbul, Turkey, 12-23 July 2004; Altan, O., Ed.; Copernicus Publications: Gottingen, Germany, 2004; Volume 35, Part B4; pp. 475-480.

10. Cardenal, J.; Delgado, J.; Mata, E.; González-Díez, A.; Remondo, J.; Díaz de Terán, J.R.; Francés, E.; Salas, L.; Bonachea, J.; Olague, I.; et al. The use of digital photogrammetry techniques in landslide instability. In Geodetic Deformation Monitoring: From Geophysical to Geodetic Roles; Gil-Cruz, J., Sanso, F., Eds.; IAG Springer Series: New York, NY, USA, 2006; pp. 259-264.

11. Prokešová, R.; Kardoš, M.; Medved'ová, A. Landslide dynamics from high-resolution aerial photographs: A case study from the Western Carpathians, Slovakia. Geomorphology 2010, 115, 90-101. [CrossRef]

12. González-Díez, A.; Fernández-Maroto, G.; Doughty, M.W.; Díaz de Terán, J.R.; Bruschi, V.; Cardenal, J.; Pérez, J.L.; Mata, E.; Delgado, J. Development of a methodological approach for the accurate measurement of slope changes due to landslides, using digital photogrammetry. Landslides 2014, 11, 615-628. [CrossRef]

13. Sandric, I.; Mihai, B.; Chitu, Z.; Gutu, A.; Savulescu, I. Object-oriented methods for landslides detection using high resolution imagery, morphometric properties and meteorological data. In Proceedings of ISPRS TC VII Symposium-100 Years ISPRS, Vienna, Austria, 5-7 July 2010; Wagner, W., Székely, B., Eds.; ISPRS: Beijing, China, 2010; Volume 38, Part 7B; pp. $486-491$.

14. Dewitte, O.; Jasselette, J.C.; Cornet, Y.; Van Den Eeckhaut, M.; Collignon, A.; Poesen, J.; Demoulin, A. Decadal-scale analysis of ground movements in old landslides in western Belgium. Eng. Geol. 2008, 99, 11-22. [CrossRef] 
15. Corsini, A.; Borgatti, L.; Cervi, F.; Dahne, A.; Ronchetti, F.; Sterzai, P. Estimating mass-wasting processes in active earth slidesEarth flows with time-series of high-resolution DEMs from photogrammetry and airborne LiDAR. Nat. Hazards Earth Syst. Sci. 2009, 9, 433-439. [CrossRef]

16. Fernández, T.; Pérez, J.L.; Colomo, C.; Cardenal, J.; Delgado, J.; Palenzuela, J.A.; Irigaray, C.; Chacón, J. Assessment of the evolution of a landslide using digital photogrammetry and LiDAR techniques in the Alpujarras Region (Granada, Southeastern Spain). Geosciences 2017, 7, 32. [CrossRef]

17. Kamps, M.T.; Bouten, W.; Seijmonsbergen, A.C. LiDAR and orthophoto synergy to optimize object-based landscape change: Analysis of an active landslide. Remote Sens. 2017, 9, 805. [CrossRef]

18. Brückl, E.; Brunner, F.K.; Kraus, K. Kinematics of a deep-seated landslide derived from photogrammetric, GPS and geophysical data. Eng. Geol. 2006, 88, 149-159. [CrossRef]

19. Eltner, A.; Kaiser, A.; Castillo, C.; Rock, G.; Neugirg, F.; Abellán, A. Image-based surface reconstruction in geomorphometryMerits, limits and developments. Earth Surf. Dyn. 2016, 4, 359-389. [CrossRef]

20. Niethammer, U.; James, M.R.; Rothmund, S.; Travelletti, J.; Joswig, M. UAV-based remote sensing of the Super-Sauze landslide: Evaluation and results. Eng. Geol. 2012, 128, 2-11. [CrossRef]

21. Fernández, T.; Pérez, J.L.; Cardenal, F.J.; Gómez, J.M.; Colomo, C.; Delgado, J. Analysis of landslide evolution affecting olive groves using UAV and photogrammetric techniques. Remote Sens. 2016, 8, 837. [CrossRef]

22. Rossi, G.; Tanteri, L.; Tofani, V.; Vannocci, P.; Moretti, S.; Casagli, N. Multitemporal UAV surveys for landslide mapping and characterization. Landslides 2018, 15, 1045-1052. [CrossRef]

23. Peppa, M.V.; Mills, J.P.; Moore, P.; Miller, P.E.; Chambers, J.E. Automated co-registration and calibration in SfM photogrammetry for landslide change detection. Earth Surf. Process. Landf. 2019, 44, 287-303. [CrossRef]

24. Cardenal, J.; Fernández, T.; Pérez-García, J.L.; Gómez-López, J.M. Measurement of road surface deformation using images captured from UAVs. Remote Sens. 2019, 11, 1507. [CrossRef]

25. Glenn, N.F.; Streutker, D.R.; Chadwick, D.J.; Thackray, G.D.; Dorsch, S.J. Analysis of LiDAR-derived topographic information for characterizing and differentiating landslide morphology and activity. Geomorphology 2006, 73, 131-148. [CrossRef]

26. Lin, M.L.; Chen, T.W.; Lin, C.W.; Ho, D.J.; Cheng, K.P.; Yin, H.Y.; Chen, M.C. Detecting large-scale landslides using Lidar data and aerial photos in the Namasha-Liuoguey Area, Taiwan. Remote Sens. 2014, 6, 42-63. [CrossRef]

27. Tarolli, P. High-resolution topography for understanding Earth surface processes: Opportunities and challenges. Geomorphology 2014, 216, 295-312. [CrossRef]

28. Li, X.; Cheng, X.; Chen, W.; Chen, G.; Liu, S. Identification of forested landslides using LiDAR data, object-based image analysis, and machine learning algorithms. Remote Sens. 2015, 7, 9705-9726. [CrossRef]

29. Pradhan, B.; Alsaleh, A. A supervised object-based detection of landslides and man-made slopes using airborne laser scanning Data. In Laser Scanning Applications in Landslide Assessment; Pradhan, B., Ed.; Springer International Publishing: Cham, Switzerland, 2017; pp. 23-50.

30. Pawluszek-Filipiak, K.; Borkowski, A. On the importance of train-test split ratio of datasets in automatic landslide detection by supervised classification. Remote Sens. 2020, 12, 3054. [CrossRef]

31. Palenzuela, J.A.; Marsella, M.; Nardinocchi, C.; Pérez, J.L.; Fernández, T.; Chacón, J.; Irigaray, C. Landslide detection and inventory by integrating LiDAR data in a GIS environment. Landslides 2015, 12, 1035-1050. [CrossRef]

32. Bossi, G.; Cavalli, M.; Crema, S.; Frigerio, S.; Quan Luna, B.; Mantovani, M.; Marcato, G.; Schenato, L.; Pasuto, A. Multi-temporal LiDAR-DTMs as a tool for modelling a complex landslide: A case study in the Rotolon catchment (eastern Italian Alps). Nat. Hazards Earth Syst. Sci. 2015, 15, 715-722. [CrossRef]

33. Liu, W.; Yamazaki, F.; Maruyama, Y. Detection of earthquake-induced landslides during the 2018 Kumamoto earthquake using multitemporal airborne Lidar data. Remote Sens. 2019, 11, 2292. [CrossRef]

34. Mora, O.E.; Lenzano, M.G.; Toth, C.K.; Grejner-Brzezinska, D.A.; Fayne, J.V. Landslide change detection based on multi-temporal airborne LiDAR-derived DEMs. Geosciences 2018, 8, 23. [CrossRef]

35. Fernández, T.; Sánchez-Gómez, M.; García, F.; Pérez-Varela, F. Cartografía de movimientos de ladera en el frente montañoso de la Cordillera Bética en el sector de Jaén. In Geotemas 13, Proceedings of the Actas del VIII Congreso Geológico de España, Oviedo, España, 17-19 June 2012; Fernández, L.P., Fernández, A., Cuesta, A., Bahamonde, J.R., Eds.; Sociedad Geológica de España: Salamanca, Spain, 2012; Volume 13, pp. 1471-1474. (In Spanish)

36. Fernández, T.; Pérez, J.L.; Cardenal, F.J.; López, A.; Gómez, J.M.; Colomo, C.; Sánchez, M.; Delgado, J. Use of a light UAV and photogrammetric techniques to study the evolution of a landslide in Jaén (Southern Spain). Int. Arch. Photogramm. Remote Sens. Spat. Inf. Sci. 2015, 40, 241. [CrossRef]

37. Carpena, R.L.; Mellado, I.; Moya, F.; Colomo, C.; Bédmar, P.; Calero, J.; Pérez, A.; Fernández, T.; Sánchez-Gómez, M.; Tovas, J. Análisis de riesgos asociados a las infraestructuras viarias de la Diputación Provincial de Jaén. In Proceedings of the IX Simposio Nacional Sobre Laderas y Taludes Inestables, Santander, Spain, 27-30 June 2017; Volume 1, pp. 335-346. (In Spanish).

38. Varnes, D.J. Slope movement, types and processes. In Landslides: Analysis and Control; Schuster, R.L., Krizek, R.J., Eds.; Transportation Research Board Special Report National Academy of Sciences: Washington, DC, USA, 1978; Volume 176, pp. 12-33.

39. Hungr, O.; Leroueil, S.; Picarelli, L. The Varnes classification of landslide types, an update. Landslides 2014, 11, 167-194. [CrossRef]

40. Roldán, F.J.; Lupiani, E.; Jerez, L. Mapa Geológico de España, Escala 1:50.000, Mapa y Memoria Explicativa; Instituto Geológico Nacional: Madrid, Spain, 1988. (In Spanish) 
41. Pérez-Valera, F.; Sánchez-Gómez, M.; Pérez-López, A.; Pérez-Valera, L.A. An evaporite-bearing accretionary complex in the northern front of the Betic-Rif orogeny. Tectonics 2017, 36, 1006-1036. [CrossRef]

42. Instituto Geográfico Nacional (IGN), Fototeca Digital. Available online: http:/ / fototeca.cnig.es/ (accessed on 31 January 2021).

43. Instituto de Estadística y Cartografía de Andalucía (IECA), Fototeca. Available online: http://www.juntadeandalucia.es/ institutodeestadisticaycartografia/fototeca/ (accessed on 31 January 2021).

44. Colomo-Jiménez, C.; Pérez-García, J.L.; Fernández-del-Castillo, T.; Gómez-López, J.M.; Mozas-Calvache, A.M. Methodology for orientation and fusion of photogrammetric and LiDAR data for multitemporal studies. Int. Arch. Photogramm. Remote Sens. Spat. Inf. Sci. 2016, XLI-B7, 639-645. [CrossRef]

45. Fernández, T.; Pérez-García, J.L.; Gómez-López, J.M.; Cardenal, J.; Calero, J.; Sánchez-Gómez, M.; Delgado, J.; Tovar-Pescador, J. Multitemporal analysis of Gully erosion in olive groves by means of digital elevation models obtained with aerial photogrammetric and LiDAR data. ISPRS Int. J. Geo-Inf. 2020, 9, 260. [CrossRef]

46. Socet Set 5.6; Bae Systems Plc.: London, UK, 2011.

47. Korsgaard, N.; Nuth, C.; Khan, S.; Kjeldsen, K.K.; Bjørk, A.A.; Schomacker, A.; Kjaer, K.H. Digital elevation model and orthophotographs of Greenland based on aerial photographs from 1978-1987. Sci. Data 2016, 3, 160032. [CrossRef] [PubMed]

48. QGIS 3. A Free and Open Source Geographic Information System. 2020. Available online: https://www.qgis.org/en/site/ (accessed on 31 January 2021).

49. Brasington, J.; Rumsby, B.T.; McVey, R.A. Monitoring and modelling morphological change in a braided gravel-bedriver using high resolution GPS-based survey. Earth Surf. Proc. Landf. 2000, 25, 973-990. [CrossRef]

50. Instituto de Estadística y Cartografía de Andalucía (IECA), Localizador de Información Geográfica de Andalucía. Available online: http: / / www.juntadeandalucia.es/institutodeestadisticaycartografia/lineav2/web/ (accessed on 31 January 2021).

51. Bannari, A.; Morin, D.; Bonn, F.; Huete, A.R. A review of vegetation indices. Remote Sens. Rev. 1995, 13, 95-120. [CrossRef]

52. Louhaichi, M.; Borman, M.M.; Johnson, D.E. Spatially located platform and aerial photography for documentation of grazing impacts on wheat. Geocarto Int. 2001, 16, 65-70. [CrossRef]

53. Wheaton, J.M.; Brasington, J.; Darby, S.E.; Sear, D.A. Accounting for uncertainty in DEMs from repeat topographic surveys: Improved sediment budgets. Earth Surf. Process. Landf. 2010, 35, 136-156. [CrossRef]

54. Hattanji, T.; Moriwaki, H. Morphometric analysis of relic landslides using detailed landslide distribution maps: Implications for forecasting travel distance of future landslides. Geomorphology 2009, 103, 447-454. [CrossRef]

55. International Union of Geological Sciences Working Group on Landslides. A suggested method for describing the rate of movement of a landslide. Bull. Eng. Geol. Environ. 1995, 52, 75-78.

56. WP/WLI. A suggested method for describing the activity of a landslide. Bull. Eng. Geol. Environ. 1993, $47,53-57$.

57. Boussouf, S.; Irigaray, C.; Chacón, J. Movimientos de ladera y factores determinantes en la vertiente septentrional de la Depresión de Granada (sector Colomera-Zagra). Rev. Soc. Geol. España 1994, 7, 251-260. (In Spanish)

58. Irigaray, C.; Fernández, T.; El Hamdouni, R.; Chacón, J. Verification of landslide susceptibility mapping. A case study. Earth Surf. Proc. Land. 1999, 24, 537-554.

59. Irigaray, C.; Fernández, T.; El Hamdouni, R.; Chacón, J. Evaluation and validation of landslide susceptibility maps obtained by a GIS matrix method: Examples from the Betic Cordillera (southern Spain). Nat. Hazards 2007, 41, 61-79. [CrossRef]

60. Reichenbach, P.; Rossi, M.; Malamud, B.; Mihri, M.; Guzzetti, F. A review of statistically-based landslide susceptibility models. Earth-Sci. Rev. 2018, 180, 60-91. [CrossRef]

61. IAEG. Commission on Landslides. Suggested nomenclature for landslides. Bull. Eng. Geol. Environ. 1990, 41, $13-16$.

62. Guzzetti, F.; Reichenbach, P.; Cardinali, M.; Galli, M.; Ardizzone, F. Probabilistic landslide hazard assessment at the basin scale. Geomorphology 2005, 72, 272-299. [CrossRef]

63. Crozier, M.J. Techniques for the morphometric analysis of landslips. Z. Geomorphol. 1973, 17, 78-101.

64. Finlay, P.J.; Fell, R.; Maguire, P.K. The relationship between the probability of landslide occurrence and rainfall. Can. Geotech. J. 1997, 34, 811-824. [CrossRef]

65. Guzzeti, F. Landslide hazard assessment and risk evaluation: Limits and prospectives. In Proceedings of the 4th EGS Plinius Conference, Mediterranean Storms, Mallorca, Spain, 2-4 October 2002.

66. Trigo, R.M.; Pozo, D.; Timothy, C.; Osborn, J.; Castro, Y.; Gámiz, S.; Esteban, M.J. NAO influence on precipitation, river flow and water resources in the Iberian Peninsula. Int. J. Clim. 2004, 24, 925-944. [CrossRef] 